INEL-95/0194

\title{
Reliability Evaluation Methodologies for Ensuring Container Integrity of Stored Transuranic (TRU) Waste
}

\author{
Karl L. Smith
}

Published June 1995

Idaho National Engineering Laboratory

Waste Operations Directorate

Lockheed Martin Idaho Technologies

Idaho Falls, Idaho $\mathbf{8 3 4 1 5}$

Prepared for the

U.S. Department of Energy

Assistant Secretary for Environmental Management

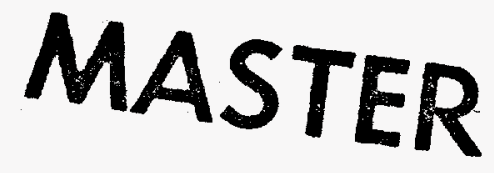

Under DOE Idaho Operations Office

Contract DE-AC07-941D13223 


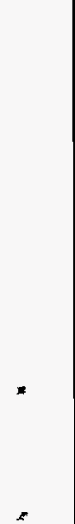




\section{DISCLAIMER}

Portions of this document may be illegible in electronic image products. Images are produced from the best available original document. 


\begin{abstract}
This report provides methodologies for providing defensible estimates of expected transuranic waste storage container lifetimes at the Radioactive Waste Management Complex. These methodologies can be used to estimate transuranic waste container reliability (for integrity and degradation) and as an analytical tool to optimize waste container integrity. Container packaging and storage configurations, which directly affect waste container integrity, are also addressed. The methodologies presented provide a means for demonstrating Resource Conservation and Recovery Act waste storage requirements.
\end{abstract}

\title{
DISCLAIMER
}

This report was prepared as an account of work sponsored by an agency of the United States Government. Neither the United States Government nor any agency thereof, nor any of their employees, makes any warranty, express or implied, or assumes any legal liability or responsibility for the accuracy, completeness, or usefulness of any information, apparatus, product, or process disclosed, or represents that its use would not infringe privately owned rights. Reference herein to any specific commercial product, process, or service by trade name, trademark, manufacturer, or otherwise does not necessarily constitute or imply its endorsement, recommendation, or favoring by the United States Government or any agency thereof. The views and opinions of authors expressed herein do not necessarily state or reflect those of the United States Government or any agency thereof. 


\section{CONTENTS}

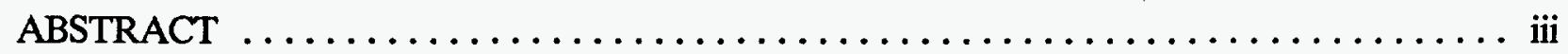

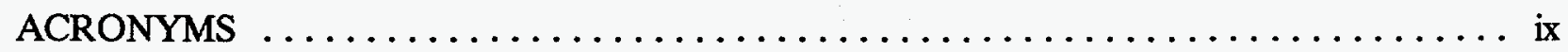

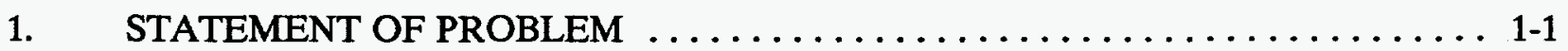

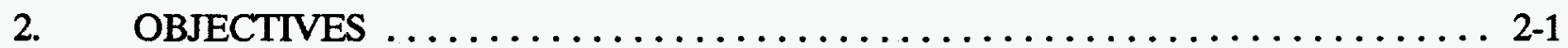

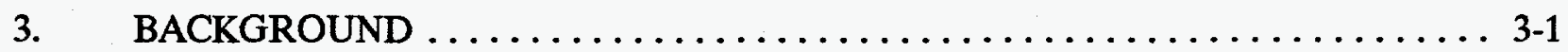

3.1 Overview of RWMC $\ldots \ldots \ldots \ldots \ldots \ldots \ldots \ldots \ldots \ldots \ldots \ldots \ldots \ldots \ldots \ldots, 1$

3.2 Storage Containers at Transuranic Storage Area $\ldots \ldots \ldots \ldots \ldots \ldots \ldots . .1$

4. CONTAINER SYSTEM RELIABILITY MODEL $\ldots \ldots \ldots \ldots \ldots \ldots \ldots \ldots$ 4-1

4.1 Introduction to Container System Reliability Model Development $\ldots \ldots \ldots$ 4-1

4.2 Basic Model Requirements $\ldots \ldots \ldots \ldots \ldots \ldots \ldots \ldots \ldots \ldots \ldots \ldots$ 4-1

4.3 Derivation of Container System Reliability Model $\ldots \ldots \ldots \ldots \ldots \ldots$ 4-4

4.4 Container Reliability Assumptions $\ldots \ldots \ldots \ldots \ldots \ldots \ldots \ldots \ldots \ldots$

4.5 Container System Reliability Sensitivity Analysis $\ldots \ldots \ldots \ldots \ldots \ldots$ 4.9

4.6 General Sensitivity Curves $\ldots \ldots \ldots \ldots \ldots \ldots \ldots \ldots \ldots \ldots \ldots \ldots \ldots$

4.7 Sensitivity Analysis for Specified Component Reliability Conditions ...... 4-11

$4.8 \quad$ Paint Failure $\ldots \ldots \ldots \ldots \ldots \ldots \ldots \ldots \ldots \ldots \ldots \ldots \ldots \ldots, 4-11$

4.9 Ignore Selected Components In The System . . . . . . . . . . . . 4-12

4.10 Component Reliabilities $\ldots \ldots \ldots \ldots \ldots \ldots \ldots \ldots \ldots \ldots \ldots \ldots, 4-12$

5. GENERAL SOLUTION FOR COMPONENT RELIABILITY AGING

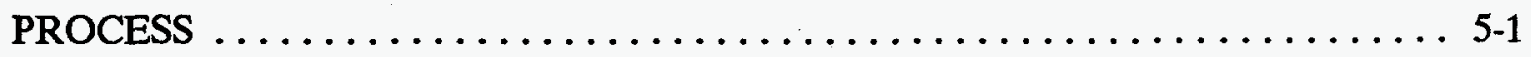

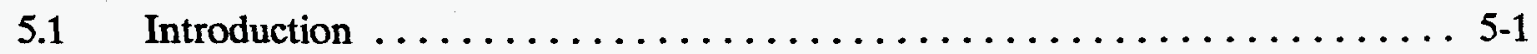

5.2 General Solution for Component Reliability $\ldots \ldots \ldots \ldots \ldots \ldots \ldots .3$

5.3 Objectives of Component Reliability Model $\ldots \ldots \ldots \ldots \ldots \ldots \ldots$. $5-5$

5.4 Component Reliability Model Assumptions $\ldots \ldots \ldots \ldots \ldots \ldots \ldots \ldots$ 5-6

5.5 Model for Reliability $\left(\mathrm{r}_{\mathrm{ij}}\right)$ of the ijth Component $\ldots \ldots \ldots \ldots \ldots \ldots \ldots$ 
5.5.1 Exponential Reliability Versus $t \ldots \ldots \ldots \ldots \ldots \ldots \ldots \ldots$

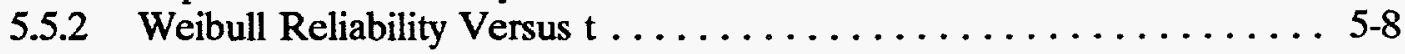

5.5 .3 Summary $\ldots \ldots \ldots \ldots \ldots \ldots \ldots \ldots \ldots \ldots \ldots \ldots \ldots \ldots$

6. IMPLEMENTATION OF THE COMPONENT RELIABILITY MODEL $\ldots \ldots \ldots$. $6-1$

6.1 Definition of Variables $\ldots \ldots \ldots \ldots \ldots \ldots \ldots \ldots \ldots \ldots \ldots \ldots \ldots \ldots$

6.2 Sample Estimates Of Reliability $\ldots \ldots \ldots \ldots \ldots \ldots \ldots \ldots \ldots \ldots \ldots \ldots$

$6.3 \quad$ Hypothetical Example $\ldots \ldots \ldots \ldots \ldots \ldots \ldots \ldots \ldots \ldots \ldots \ldots \ldots \ldots$

6.3.1 Illustration for Exponential $\mathrm{R}(\mathrm{t} \mid \mathrm{y}) \ldots \ldots \ldots \ldots \ldots \ldots \ldots \ldots \ldots$

6.3.2 Illustration For Linear $\mathrm{R}(\mathrm{t} \mid \mathrm{y}) \ldots \ldots \ldots \ldots \ldots \ldots \ldots \ldots . \ldots \ldots \ldots$

6.3 .3 Comparison Summary $\ldots \ldots \ldots \ldots \ldots \ldots \ldots \ldots \ldots \ldots \ldots$

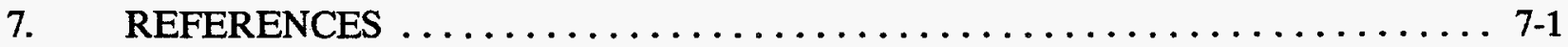

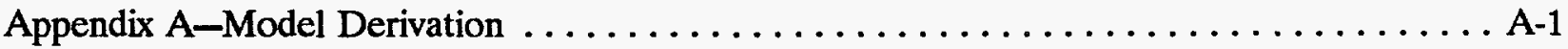

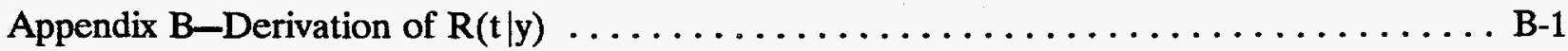

\section{FIGURES}

4-1. Waste container barrier schematic for typical DOT 17 C 55-gal steel drum ......4-3

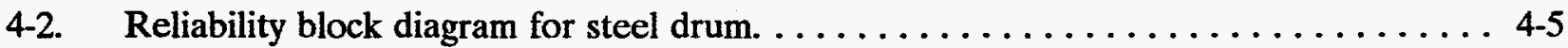

4-3. Container component reliabilities $\left(r_{j i}\right)$ to maintain waste system containment reliability at $r_{i}=0.999999$.

6-1. Weibull probability plot for hypothetical data from Table $6-2 \ldots \ldots \ldots \ldots \ldots$

\section{TABLES}

3-1. Breakdown of TSA waste by container type (see RWMC SAR, Table 5-12) . . . . . 3-2

3-2. Number of waste storage containers stored in TSA air support buildings. . . . . . . 3-4

4-1. Container system reliability sensitivity analysis for the conditions

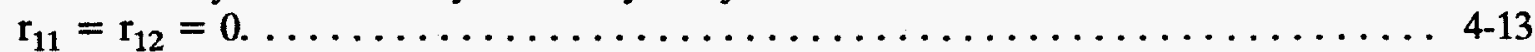

4-2. Container system reliability sensitivity analysis for either the conditions $r_{11}=0$, and $r_{12}=0.5$ or $r_{11}=0.5$, and $r_{12}=0$

4-3. Summary of component reliabilities. $\ldots \ldots \ldots \ldots \ldots \ldots \ldots \ldots \ldots \ldots$

5-1. Types of life data (Nelson 1990$). \ldots \ldots \ldots \ldots \ldots \ldots \ldots \ldots \ldots \ldots \ldots \ldots$ 
6-1. Hypothetical data for sample size $[\mathrm{n}(\mathrm{t} \mid \mathrm{y})]$ and number of successes $[\mathrm{g}(\mathrm{t} \mid \mathrm{y})]$ versus component age $(\mathrm{t})$ in months. $\ldots \ldots \ldots \ldots \ldots \ldots \ldots \ldots \ldots \ldots \ldots \ldots \ldots \ldots, 2$

6-2. Estimated $R(t \mid y)$ using Equation $(5-11)$ and the data from Table $6-1 \ldots \ldots \ldots \ldots 6-3$ 


\section{ACRONYMS}

DOE U.S. Department of Energy

DOT U.S. Department of Transportation

INEL Idaho National Engineering Laboratory

LLW low-level waste

RCRA Resource Conservation and Recovery Act

RWMC Radioactive Waste Management Complex

SAND Sandia designed

SAR safety analysis report

SDA Subsurface Disposal Area

SWEPP Stored Waste Examination Pilot Plant

TRU transuranic

TSA Transuranic Storage Area 


\section{Reliability Evaluation Methodologies for Ensuring Container Integrity of Stored Transuranic (TRU) Waste}

\section{STATEMENT OF PROBLEM}

Container integrity, preservation of container integrity, and loss of container integrity are beginning to be recognized as problems common to all U.S. Department of Energy (DOE) facilities. The materials making up a waste container configuration (e.g., container wall, protective coverings such as paint, and liners) are the initial defense against radionuclide release. Furthermore, container storage environment is a key element in preserving container integrity. Container integrity is an important environmental and waste management consideration in the strategy for safe waste storage (Plansky 1994).

The definition of container integrity and degradation requires the specification of characteristics that containers must have. Container integrity requirements involve health and safety, finish, structure, and assembly.

A degraded container is defined as a container whose use has become impaired because of age-related, handling, storage environment, or other causes, and that has reached the point where the container cannot meet the minimum applicable acceptance criteria for safe handling or storage (Plansky 1994).

A prevalent type of storage container used for Radioactive Waste Management Complex (RWMC) waste storage is the U.S. Department of Transportation (DOT) 17C 55-gal steel drum. Drum container integrity is tied to RWMC operational needs. The RWMC safety analysis report (SAR) and Resource Conservation and Recovery Act (RCRA) Part B permit require a container that can be safely handled, will withstand being dropped, can support four fully loaded drums above it in storage, poses no fire threat, and does not visibly leak dangerous material(s) (Plansky 1994). 


\section{OBJECTIVES}

It is necessary to develop methodologies for providing defensible estimates of expected storage container lifetimes for current and alternative TRU waste storage configurations. Such methodologies can be used to estimate the reliability of containers used to store transuranic (TRU) waste and as an analysis tool to focus improvements that would enhance waste container integrity. Containment system reliability is defined as the probability of performing a specified waste storage containment function or mission under specified conditions for a specified time. The methodologies that are developed provide a means for demonstrating RCRA waste storage requirements.

Of significant interest in determining container lifetimes is the rate of corrosion of carbon steel containers (e.g., DOT 17C 55-gal drums) used to store TRU waste. The significance of corrosion and the time frame during which container integrity is believed adequate can be evaluated using the methodologies developed in this report.

A typical waste container packaging configuration used to store TRU waste within the air support weather shield buildings at the Idaho National Engineering Laboratory (INEL) RWMC involves DOT 17C 55-gal steel drums and includes the following factors:

- The drums are fabricated using 16-gauge (i.e., 0.0598 in. nominal thickness) low carbon steel material

- The interior drum surfaces are painted with one coat of standard rust-inhibiting paint

- The exterior drum surfaces are primed and painted with a white- or buff-colored paint

- The drums are lined with a 90-mil high-density polyethylene liner

- The contents within the drums are usually enclosed in one or more polyethylene or polyvinyl chloride plastic bags

- The drum heads are fastened to the drums using a gasket, a 12-gauge bolting ring, and a 5/8-in.-diameter bolt

- The interior of most drums is vented using a carbon filter or styrene butadiene semipermeable gasket.

A fundamental objective of the methodologies developed and presented in this report is to evaluate drum container integrity and degradation based on a consideration of factors such as those listed above. Other different types of container packaging and storage configurations are also of interest. The methodology of this report is directly applicable to drums, but can also be expanded to other types of storage containers. The purpose and primary interest is the application of report methodologies as a means for clearly establishing and maintaining container integrity for the waste stored at the RWMC. 


\section{BACKGROUND}

\subsection{Overview of RWMC}

The RWMC is a government-owned, contractor-operated nonreactor nuclear facility located in the southwest corner of the INEL. It is a controlled access area with facilities and equipment to manage low-level, mixed, and TRU solid radioactive waste generated by the INEL and other DOE laboratories and operations. The primary mission of the RWMC is to safely dispose of INEL-generated low-level waste (LLW) and to temporarily store mixed TRU waste, which will be retrieved, nondestructively examined, and shipped to a disposal facility such as the Waste Isolation Pilot Plant in Carlsbad, New Mexico.

The RWMC is divided into three general areas:

- The Subsurface Disposal Area (SDA), which is used for permanent disposal of LLW. TRU waste received before 1970 was also buried in the SDA. The SDA includes Pad A (formerly the Transuranic Disposal Area), trenches, concrete and soil vaults, and pits used for disposal of LLW.

- The Transuranic Storage Area (TSA), which is located in the southeast portion of the RWMC. It is used for examination, segregation, certification, and interim storage of TRU waste. The TSA consists of storage pads, the Intermediate-Level Transuranic Storage Facility, and the Stored Waste Examination Pilot Plant (SWEPP). SWEPP includes the Drum Vent Building, the Certified and Segregated Waste Storage Building, the Transuranic Package Transporter-II Loading Facility, and the Air Support Building-II.

- $\quad$ The Administrative Area (EG\&G Idaho 1994).

Of these three major areas, TSA is of primary interest in this report.

\subsection{Storage Containers at Transuranic Storage Area}

Most retrievable stored waste containers at TSA are stacked in arrays on concrete and asphalt pads, as described in Section 4.3.1 of the RWMC SAR (EG\&G Idaho 1994). Containers approved for storage on the TSA pads include 55- and 30-gal steel drums, with a DOT designation of $17 \mathrm{C}, 17 \mathrm{H}$ (distinguished mainly by wall thickness), or $6 \mathrm{M}$ (essentially a $17 \mathrm{C}$ drum with an inner container, a metal cylinder with maximum diameter of $13.3 \mathrm{~cm}$, which is centered in the outer drum by fiberboard disks). A variety of wooden boxes and steel bins are also approved for storage on the TSA pads. In some cases, smaller containers are overpacked in larger ones, such as 30-gal drums in 55-gal drums, 55-gal drums in 83-gal drums (83-gal drums are not used as primary containers), and several steel drums in a single steel bin (EG\&G Idaho 1994).

Table 3-1 provides a breakdown of TSA waste by container type. Table 3-1 shows that the metal drum is the predominant type of container at TSA, since 127,667 (i.e., more than 91\%) of the containers are metal drums. Most containers on older pads are covered with soil.

More recently stored waste container arrays are protected from the weather by an air support building, and future arrays will be placed in metal buildings. The information provided by 
Table 3-1. Breakdown of TSA waste by container type (see RWMC SAR, Table 5-12).,

\begin{tabular}{lr} 
Container type & Number \\
\hline BIN & 550 \\
BLM & 127,667 \\
BXC & 1 \\
BXW & 8,800 \\
BXM & 2,356 \\
RD5 & 7 \\
RDL & 16 \\
Other & 27 \\
Total containers & 139,424
\end{tabular}

a. The data in this table were extracted from the dBASE version of the Historical and Current RWMIS databases. These data span the following disposal dates: 11/10/70 to 12/9/83 (Historical RWMIS) and $1 / 3 / 84$ to $1 / 28 / 92$ (Current RWMIS).

b. Taken from the Safety Analysis Report for the Radioactive Waste Management Complex at the Idaho National Engineering Laboratory (EG\&G Idaho 1994).

BXC-cardboard box

BXM-metal box

BLM-metal barrel (drum)

BXW-wooden box (fiberglass reinforced polyester and plywood)

BIN-bin (other than Waste Experimental Reduction Facility

RD5-metal barrel, 55 gal, without liner

RDL-metal barrel, 55 gal, with liner 
Table 3-2 was extracted from the indicated references and shows that the DOT 17C 55-gal steel drum (see Note e of Table 3-2) is the predominant type of waste container configuration for storing solid waste in the TSA air support buildings. However, alternate types of storage configurations involve small numbers of Sandia designed (SAND) and TX-4 metal boxes. Table 3-2 indicates that fiberglass reinforced polyester-coated and wooden boxes are recommended for overpacking. Several of the other container configurations involve quantities of free liquids and are also recommended for overpacking.

Although, the reliability of the DOT 17C 55-gal steel drum configuration is of primary interest and is addressed in the next section, the system reliability of other alternative types of container storage configurations, including overpacking configurations, could also be modeled. 
Table 3-2. Number of waste storage containers stored in TSA air support buildings.

\begin{tabular}{|c|c|}
\hline Number & Description \\
\hline $28,500^{a}$ & DOT $17 \mathrm{C}$ drums ${ }^{a, d, e}$ that contain solid waste without free liquid and that have not been subjected to underground environments. \\
\hline $2,000^{a}$ & DOT $17 \mathrm{C}$ drums that contain small quantities of free liquids. \\
\hline $2,500^{a, c, d}$ & $\begin{array}{l}\text { DOT } 17 \text { C } 55 \text {-gal steel drums that were removed from earth-covered storage in } 1984 f \text { It is prudent to evaluate the amount of corrosion and decide if overpacking } c \\
\text { is required. }\end{array}$ \\
\hline $33,000^{a, d}$ & The total number (i.e., $28,500+2,000+2,500$ ) of DOT $17 \mathrm{C} 55$-gal carbon steel drums stored in air support buildings. \\
\hline $4,418^{c, d}$ & DOT 17C 55-gal drums with free liquids with a pH of between 3 and 12 . Free liquids are contained within the 90-mil liner. \\
\hline $4137^{b, c}$ & DOT 17C 55-gal steel drums with 90-mil high-density polyethylene liners that contain free liquids of pH 12. \\
\hline $340^{b}$ & $\begin{array}{l}\text { DOT 17C 55-gal steel drums that were removed from the earthen-covered Pad } 1, \text { Cell } 5 \text { and placed in the air support buildings. It is prudent to Overpacth,c in } \\
83 \text {-gal steel drums with } 90 \text {-mil high-density rigid polyethylene liners. }\end{array}$ \\
\hline $236^{b, c, d}$ & DOT $17 \mathrm{C}$ drums with free liquids between liners and interior walls. It is prudent to overpact, ${ }^{b} c$ these drums. \\
\hline $211^{b, c, d}$ & DOT $17 \mathrm{C}$ drums with packaged liquids within the high-density polyethylene rigid liners; stored in plastic containers. \\
\hline $1,439^{b, c, d}$ & $\begin{array}{l}\text { SAND metal boxes that are constructed of 14-gauge (i.e., } 0.0667 \text { in.) steel and lined with an } 11 \text {-mil polyvinyl chloride liner. There is a fiberboard container between } \\
\text { the metal box and the liner. }\end{array}$ \\
\hline $29^{b, c, d}$ & $\begin{array}{l}\text { TX-4 metal boxes that are constructed of } 14 \text {-gauge (i.e., } 0.0667 \text { in.) steel and lined with an } 11 \text {-mil polyvinyl chloride liner. There is a fiberboard container between } \\
\text { the metal box and the liner. }\end{array}$ \\
\hline $161^{b, c}$ & Fiberglass reinforced polyester coated boxes. Recommend to overpack ${ }^{b}$ with metal boxes. \\
\hline $51^{b, c}$ & Wooden boxes that contain solid waste that are stored in the air support buildings. Recommend to overpack ${ }^{b}$ with metal boxes. \\
\hline \multicolumn{2}{|c|}{ a. Spaletta 1990a. } \\
\hline \multicolumn{2}{|c|}{ b. Spaletta 1990 b. } \\
\hline \multicolumn{2}{|c|}{ c. Spaletta $1990 \mathrm{c}$. } \\
\hline \multicolumn{2}{|c|}{ d. EG\&G Idaho 1994.} \\
\hline $\begin{array}{l}\text { e. The DO' } \\
\text { inhibiting pa } \\
\text { the liner are } \\
5 / 8 \text {-in.-diam }\end{array}$ & $\begin{array}{l}\text { C 55-gal drum is fabricated from 16-gauge, } 0.0598 \text {-in. nominal thickness, low-carbon steel. The interior drum surfaces are painted with one coat of standard rust- } \\
\text { The exterior surfaces are primed and painted with a white or buff paint. The drums are lined with a } 90 \text {-mil, high-density polyethylene liner, and the contents within } \\
\text { ally enclosed in one or more polyethylene or polyvinyl chloride plastic bags. The drum heads are fastened to the drums using a gasket, a } 12 \text {-gauge bolting ring, and a } \\
\text { bolt. The interior of most drums is vented using a carbon filter or styrene butadiene semipermeable gasket. }\end{array}$ \\
\hline $\begin{array}{l}\text { f. DOT } 170 \\
\text { corrosion or }\end{array}$ & $\begin{array}{l}\text { ums removed from the earth-covered Pad 1, Cell } 5 \text {, and placed in the air support buildings. A visual examination of the outer surfaces revealed evidence of localized } \\
\text { ne drums. }\end{array}$ \\
\hline
\end{tabular}




\section{CONTAINER SYSTEM RELIABILITY MODEL}

\subsection{Introduction to Container System Reliability Model Development}

Nuclear waste that is stored in containers cannot reach the outside environment unless some of the containers fail. The integrity of the container shell can be degraded (e.g., by rough handling) so that the container is no longer adequate for storing waste. The causes of container degradation and the problems it can cause are varied. A number of potential container degradation failure modes could be defined and each would require investigation. However, it is generally believed that the most likely container failure mode is the gradual corroding and degradation of container walls. Such container wall corrosion degradation can be due to either external or internal influences.

In fact, many of the waste containers stored at the RWMC have experienced, or are experiencing, degradation from corrosion. Therefore, the initial thrust of the reliability methodology of this report will consider corrosion failure modes. Internal corrosion of waste containers may occur when waste contents react with the inside wall of the container material during storage. External corrosion could occur as a result of the storage environment. The containment of waste for the required storage time depends, to a large extent, on the ability of the steel drum to withstand the effects of corrosion.

Consider two different types of drum corrosion failure modes:

- Breached. Breached means wall penetration in a small area, pitting, etc. Some localized areas corrode more rapidly than others and appear as pits, while the rest of the surface corrodes more slowly and evenly.

- Lost structural integrity. Loss of structural integrity from corrosion means that large areas have been penetrated or nearly penetrated such that normal drum handling stresses would collapse the drum.

It appears that the breach failure mode is of greatest interest since, for retrievable waste containers, it is undesirable to let corrosion progress to the loss of structural integrity. If liquids are being stored, a breach penetration could easily result in the loss of liquid from the container. A small breach penetration may not be quite as serious for containers that are used to store solid waste. However, in either case, the waste (either liquid or solid) is supposed to remain sealed in the container and a corrosion breach is undesirable.

\subsection{Basic Model Requirements}

The role of component redundancy is a well established reliability principle; for example, the duplication of equipment elements in electronic or mechanical systems provides alternative functional components to ensure system operation even when there are individual component failures. This same principle is also recognized as being applicable to the storage of nuclear waste.

It can be shown that containers with multiple barrier layers may be much more effective than single-layer containers for isolating waste for long periods of time. For example, in the case of the Yucca Mountain repository in Nevada, U.S. Nuclear Regulatory Commission regulations 
state that containment of radioactivity must be "substantially complete" for the first 1,000 years after closure of the facility (Bradford 1993). Such long containment times are essentially unachievable with single barrier systems. However, under reasonably attainable assumptions concerning individual process barrier failures, very high reliability of a multiple barrier container system can be achieved and demonstrated. The reliability of multiple barrier containers can be increased by either increasing the reliability of individual barriers, increasing the number of barriers, or using both of these design techniques.

Containment system reliability is defined as the probability of performing a specified waste storage containment function or mission under specified conditions for a specified time. Such a system reliability can be estimated using the reliability model developed in this section. The model considers a number of factors. For example, components that act as waste seal barriers to restrict the loss of container contents may include the container wall, the container liner, and plastic bags. The liner may also serve to protect the inside of the container from potentially corrosive waste material contents. There are also components (e.g., paint, tar coating, and galvanization) that are not waste seal barriers, but function to enhance the performance of the system by protecting the container wall material.

Figure 4-1 is a schematic showing the sequence of container barriers that would have to fail in order to lose containment of stored waste material. First, the waste is enclosed in plastic bag(s), then there is a liner that must be penetrated, and finally the container wall must be breached. In other words, the waste material is sealed in a container with several barriers, each of which must be breached before the waste material can escape.

Some of the factors considered in the container system reliability model are as follows.

- Barriers that act as waste seals may include the following types of items

- $\quad$ Plastic bag

- Polyethylene liner

- Container wall (e.g., carbon steel drum wall)

- Items that are not waste barriers (i.e., not waste seals), but act to retard corrosion

- Standard rust-inhibiting paint on the inner side of the drum wall

- White or buff paint on the outside of the drum

- Container corrosion acts from two directions

- Inside wall corrosion

- $\quad$ Outside wall corrosion.

Figure 4-1 provides a representation of these factors. In addition, the following additional factors should be considered in developing an adequate system reliability model for assessing containment integrity: 


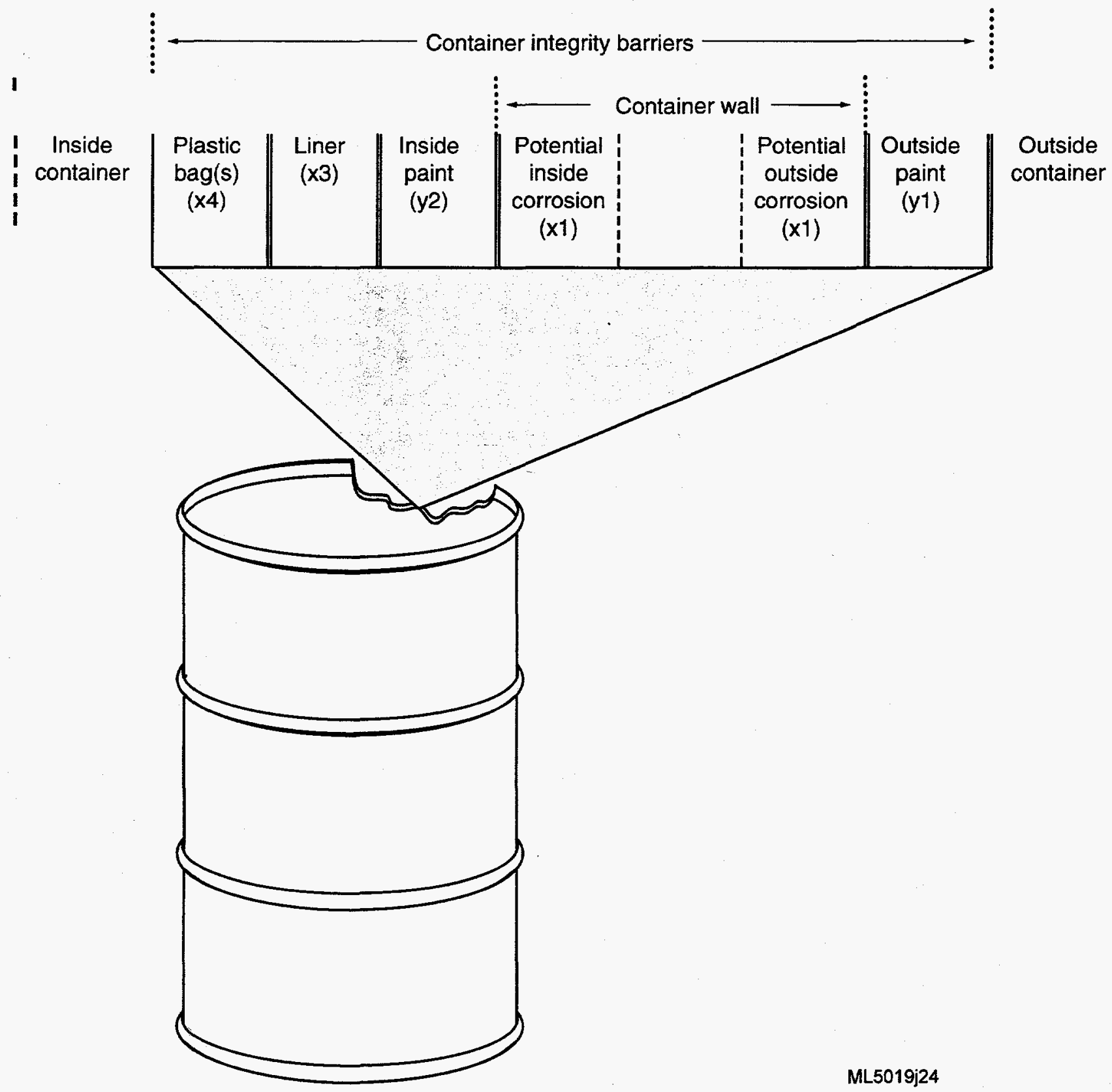

Figure 4-1. Waste container barrier schematic for typical DOT 17C 55-gal steel drum. 
- The need to be able to model multiple plastic containers inside the container (e.g., drum)

- The need to be able to model various types of storage containers (drums, boxes, etc.)

- The need to be able to relate the model to the operation of the system in the storage environment (e.g., to storage humidity and temperature). Corrosion rates appear to be influenced by cyclic environmental changes. For example, cycling changes in temperature and humidity that may make corrosion worse. Corrosion rates appear to be higher when containers are covered with soil.

Figure 4-1 applies primarily to the 55-gal drum waste containment system. For other systems, it may be necessary to incorporate additional factors. (For example, the fiberboard container between the metal box and liner of SAND and TX-4 metal boxes, or the double drum system arrangement in the 83-gal drum overpack.) It may also be necessary to model the plywood or dense plastic inserts placed on the inner bottom surface of the dense polyethylene liner overpack. The inserts protect the overpack liner from mechanical damage in the areas in contact with the relatively sharp bottom surfaces of the steel drums being overpacked.

\subsection{Derivation of Container System Reliability Model}

The container system reliability block diagram (Figure 4-2) for the typical storage drum configuration shows that there are three possible paths to achieve waste material containment (i.e., container success). For this diagram, each filled (solid) line indicates a success path, while an unfilled line indicates a failure path. Figure 4-2 shows that the plastic bag success path is given with reliability $r_{11}$. On the other hand, the plastic bag failure path or unreliability is given by $1-r_{11}$, and is indicated by the unfilled line in Figure 4-2.

Each of the container components has a reliability $\left(r_{1 j}\right.$, for $\left.j=1,2,3,4\right)$ as specified by Figure 4-2. It should be noted that all of the $r_{1 j}$ are probabilities and, therefore, their numerical values must be in the range from 0 to 1 . A discussion of techniques for obtaining estimated values for these respective component reliabilities will be postponed to later sections of this report.

To develop the reliability of the containment system it is necessary to determine the reliability associated with each success path and then sum these reliabilities. There are three success paths indicated by Figure 4-2. The respective reliabilities for each path are $r_{11},\left[\left(1-r_{11}\right)\right.$ $\left.r_{12}\right]$, and $\left[\left(1-r_{11}\right)\left(1-r_{12}\right) r_{13} r_{14}\right]$. The success path reliability determinations require that the component events be statistically independent, which is the justification for multiplying the individual reliabilities [e.g., $\left(1-r_{11}\right) \times r_{12}$ ]. To preserve containment wall integrity, the third success path indicated by Figure 4-2 requires that there cannot be a failure from either or both inside or outside corrosion. A success (i.e., no corrosion breach) is required for both inside and outside types of corrosion. Finally, the container system reliability is the sum of these three success path reliabilities and is the basis for the container system reliability model given by Equation (4-1). 


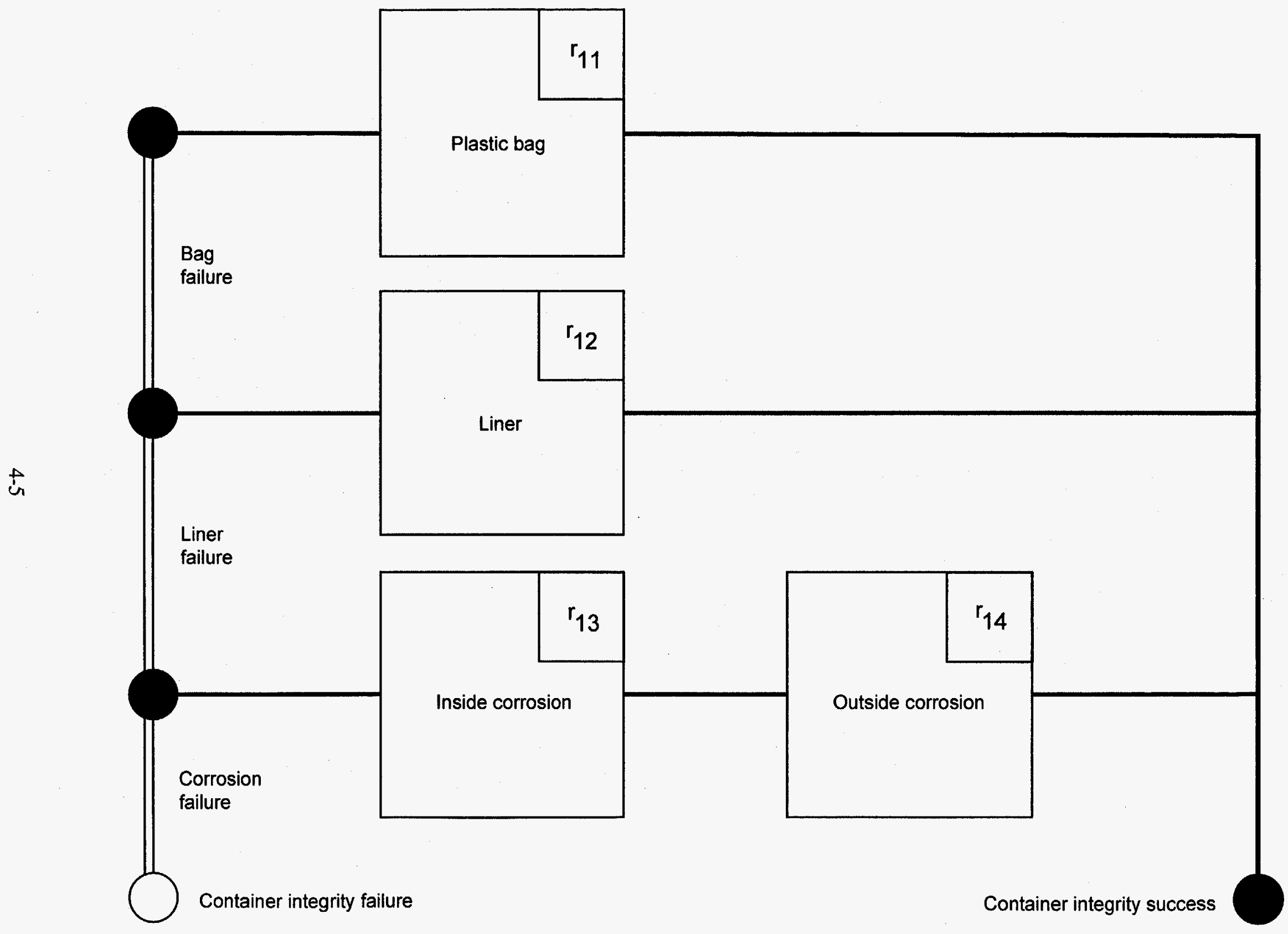

Figure 4-2. Reliability block diagram for steel drum. 
$r_{1}=r_{11}+\left(1-r_{11}\right) r_{12}+\left(1-r_{11}\right)\left(1-r_{12}\right) r_{13} r_{14}$

where

$r_{1}=r_{i=1}$ container system reliability for the $i=1$ type of container (DOT 17C 55-gal steel drum)

$\mathrm{r}_{11}=\quad$ plastic bag component reliability

$r_{12}=\quad$ liner component reliability

$r_{13}=\quad$ inside container wall (noncorrosion) component reliability

$\mathbf{r}_{14}=\quad$ outside container wall (noncorrosion) component reliability.

The reliability block diagram of Figure 4-2 shows how the component events are assumed to interact with each other to result in either containment failure or successful containment integrity. A containment system failure occurs when all three components fail (e.g., are breached).

Examination of Figure 4-1 shows that both the inner and outer container walls are painted. One function of the paint is to protect the inner and outer metal surfaces against corrosion. Consequently, Equations (4-2) and (4-3) can be used to determine outer [Equation (4-2)] and inner [Equation (4-3)] corrosion component reliabilities $r_{14}$ and $r_{13}$ based on the consideration of paint component reliabilities. Equations (4-2) and (4-3) were developed using Bernoulli trial and conditional probability relationships (Parzen 1960).

$r_{14}=\left(r_{x 1=1 \mid y 1=1}\right) r_{y 1=1}+\left(r_{x 1=1 \mid y 1=0}\right) r_{y 1=0}$

where

$$
\begin{array}{ll}
\mathrm{r}_{14} & =\text { outside container wall (noncorrosion) component reliability } \\
\mathrm{y} 1 & =\left\{\begin{array}{l}
1 \text { nonfailure of outside paint } \\
0 \text { failure of outside paint }
\end{array}\right. \\
\mathrm{x} 1 & =\begin{array}{l}
1 \text { nonfailure by outside corrosion } \\
0 \text { failure by outside corrosion }
\end{array} \\
\mathrm{r}_{\mathrm{x} 1=1 \mid \mathrm{y} 1=1} & \begin{array}{l}
\text { Outside container wall (noncorrosion) component reliability given } \\
\text { nonfailure of outside paint }
\end{array} \\
\mathrm{r}_{\mathrm{x} 1=1 \mid \mathrm{y} 1=0} & =\begin{array}{l}
\text { outside container wall (noncorrosion) component reliability given } \\
\text { failure of outside paint. }
\end{array} \\
\mathrm{r}_{\mathrm{y} 1=1} & =\text { outside paint component reliability } \\
\mathrm{r}_{\mathrm{y} 1=0} & \left.=\text { outside paint component unreliability (NOTE: } \mathrm{r}_{\mathrm{y} 1=0}=1-\mathrm{r}_{\mathrm{y} 1=1}\right) .
\end{array}
$$


$r_{13}=\left(r_{x 2=1 \mid y 2=1}\right) r_{y 2=1}+\left(r_{x 2=1 \mid y 2=0}\right) r_{y 2=0}$

where

$$
\begin{array}{ll}
r_{13} & =\text { inside container wall (noncorrosion) component reliability } \\
y 2 & =\left\{\begin{array}{l}
1 \text { nonfailure of inside paint } \\
0 \text { failure of inside paint }
\end{array}\right. \\
x 2 & =\begin{array}{l}
1 \text { nonfailure by inside corrosion } \\
0 \text { failure by inside corrosion }
\end{array} \\
r_{x 2=1 \mid y 2=1} & \begin{array}{l}
\text { inside container wall (noncorrosion) component reliability given } \\
\text { nonfailure of inside paint }
\end{array} \\
r_{x 2=1 \mid y 2=0} & =\begin{array}{l}
\text { inside container wall (noncorrosion) component reliability given failure } \\
\text { of inside paint }
\end{array} \\
r_{y 2=1} & =\text { inside paint component reliability } \\
r_{y 2=0} & =\text { inside paint component unreliability (NOTE: } r_{y 2=0}=1-r_{y 2=1} \text { ). }
\end{array}
$$

The corrosion component reliabilities as provided by Equations (4-2) and (4-3) can be substituted into Equation (4-1) to obtain Equation (4-4). Equation (4-4) is a container system reliability model that includes the factors indicated by Figure 4-1.

$$
\begin{aligned}
r_{1}= & r_{11}+\left(1-r_{11}\right) r_{12}+\left(1-r_{11}\right)\left(1-r_{12}\right) r_{13} r_{14} \\
= & r_{11}+\left(1-r_{11}\right) r_{12}+\left(1-r_{11}\right)\left(1-r_{12}\right)\left[\left(r_{x 2}=1 \mid y 2=1\right) r_{y 2=1}\right. \\
& \left.+\left(r_{x 2=1 \mid y 2=0}\right) r_{y 2=0}\right]\left[\left(r_{x 1=1 \mid y 1=1}\right) r_{y 1=1}+\left(r_{x 1=1 \mid y 1=0}\right) r_{y 1=0}\right]
\end{aligned}
$$

where

$$
\begin{aligned}
& r_{1}=\begin{array}{l}
\text { container system reliability for the } i=1 \text { type of container (i.e., DOT 17C } 55 \\
\text { gallon steel drum) }
\end{array} \\
& r_{11}=\text { plastic bag component reliability } \\
& r_{12}=\text { liner component reliability } \\
& r_{13}=\text { inside container wall (noncorrosion) component reliability } \\
& \quad=\left(r_{x 2=1 \mid y 2=1}\right) r_{y 2=1}+\left(r_{x 2=1 \mid y 2=0}\right) r_{y 2=0} \\
& r_{14}=\text { outside container wall (noncorrosion) component reliability. } \\
& \quad=\left(r_{x 1=1 \mid y 1=1}\right) r_{y 1=1}+\left(r_{x 1=1 \mid y 1=0}\right) r_{y 1=0}
\end{aligned}
$$


NOTE:

- See Equation (4-2) for definitions of inside paint conditional corrosion reliabilities: $\left(r_{x 2=1 \mid y 2=1}\right)$ and $\left(r_{x 2=1 \mid y 2=0}\right)$

- See Equation (4-2) for definitions of inside paint component reliabilities: $r_{\mathrm{y} 2=1}$ and $\mathrm{r}_{\mathrm{y} 2=0}$

- See Equation (4-3) for definitions of outside paint conditional corrosion reliabilities: $\left(r_{x 1=1 \mid y 1=1}\right)$ and $\left(r_{x 1=1 \mid y 1=0}\right)$

- See Equation (4-3) for definitions of outside paint component reliabilities: $r_{y 1=1}$ and $r_{y 1=0}$.

This model [i.e., Equation (4-4)] can also be modified to provide a basis for a generalization to other types of storage container systems (e.g., SAND and TX-4 metal boxes). The potential influence of storage environmental factors can be incorporated into the model by estimating component reliabilities based on appropriate data sampling categorization factors.

\subsection{Container Reliability Assumptions}

Two basic assumptions underlying the reliability model [i.e., Equation (4-1)] are as follows:

- The component event outcomes are represented as Bernoulli trials (i.e., with a success or failure outcome)

- Statistical independence of component events.

The Bernoulli trial assumption appears realistic, since this is based on an appropriate definition of a success or failure for an observed outcome. The manner of specifying success or failure is considered in later sections of this report.

The assumption of statistical independence is more difficult to justify. For example, a common cause event (e.g., puncturing a drum with a forklift tine) might cause all components to fail simultaneously. However, a common cause failure scenario for corrosion is not immediately apparent.

It should be noted that, depending on the type of waste that is stored in a container, a failure of the plastic bag could result in a more rapid deterioration of the liner and eventually the inside drum wall. That is, the drum wall might corrode from inside the drum at a faster rate with failures of the plastic bag(s) and liner. It is possible to account for such situations by generalizing the model to eliminate the independence assumption by using the mathematics of conditional probability; however, this refinement is beyond the scope of the present discussion. report.

A further discussion of component reliability model assumptions is provided later in this 


\subsection{Container System Reliability Sensitivity Analysis}

In order to arrive at a value for container system reliability, it is necessary to have component reliability values (i.e., the $r_{1 j}$ ); a means of obtaining estimates of these will be considered later in this report. However, it is also desirable to evaluate Equation (4-1) for sensitivity to the individual component reliabilities. The results of such a sensitivity analysis are presented in Figure 4-3. An important feature is that the redundancy (i.e., multiple success paths as shown by Figure 4-2) of components results in an overall system that can be highly reliable in spite of the fact that the individual components are only moderately reliable.

\subsection{General Sensitivity Curves}

Figure 4-3a and 4-3b graphically summarize the results of a sensitivity analysis for the ith type of waste containment system (e.g., let $i=1$ for the DOT $17 \mathrm{C}$ drum configuration). The $r_{i j}$ given by the figures refer to component reliabilities for the ith container configuration type and the jth component reliability. The curves for these figures show the tradeoffs in component reliabilities necessary to maintain container system reliability at $r_{i=1}=0.999999$. Figures 4-3a and 4-3b show that, for the indicated waste containment system (i.e., Figure 4-2), only moderately reliable components can lead to an extremely reliable system.

As an illustration for one of innumerable combinations, Figure 4-3a shows how the waste container system reliability can be maintained at $r_{i=1}=0.999999$ based on plastic bag component reliability $\left(r_{11}=0.7\right)$ and various combinations of the remaining component reliabilities [e.g., liner $\left(r_{12}=0.99983\right)$, inside corrosion $\left(r_{13}=0.99\right)$, and outside corrosion $\left.\left(r_{13}=0.99\right)\right]$. In a similar way, Figure 4-3b can be used to show how waste container system reliability can be maintained at $r_{i=1}=0.999999$, based on a higher plastic bag component reliability $\left(r_{11}=0.9\right)$ and various combinations of the remaining component reliabilities [e.g., liner $\left(r_{12}=0.9993\right)$, inside corrosion $\left(r_{13}=0.99\right)$, and outside corrosion $\left(r_{14}=0.99\right)$. Figure 4-3 can be used to obtain approximate component reliability values that can then be substituted into Equation (4-1) to perform a calculational cross-check of the actual value of $r_{i=1}$ for the specified component reliabilities. The curves (i.e., Figures 4-3a and 4-3b) are general in the sense that they can apply to any system with component reliabilities that correspond to the container barrier reliability block diagram given by Figure 4-2. The curves define a multi-dimensional surface that depends on the range of component reliabilities.

The sensitivity curves are based on solving the reliability equation [i.e., Equation (4-1)] for the $r_{i 4}$ component reliability as a function of the system reliability $\left(r_{i=1}\right)$ and the remaining component reliabilities. It should be remembered that all of the reliabilities are constrained to the range from 0 to 1 . Consequently, if, for a particular combination of $r_{i=1}, r_{11}, r_{12}, r_{13}$, the calculated value of $r_{14}$ is greater than 1 , then the specified system reliability of $r_{i=1}$ cannot be achieved for the indicated component reliabilities. In this case, it is necessary to increase the values of some of the component reliabilities until the value of $r_{14}$ is less than or equal to 1 .

Examination of the plotting scales for these figures indicates that both the vertical and horizontal scales are reversed logarithmically. This plotting transformation has the advantage of extending the plotting data range by using logarithms and also eliminates the requirement for plotting negative numbers since reliabilities are numbers less than 1 and logarithms of numbers less than 1 are negative. 


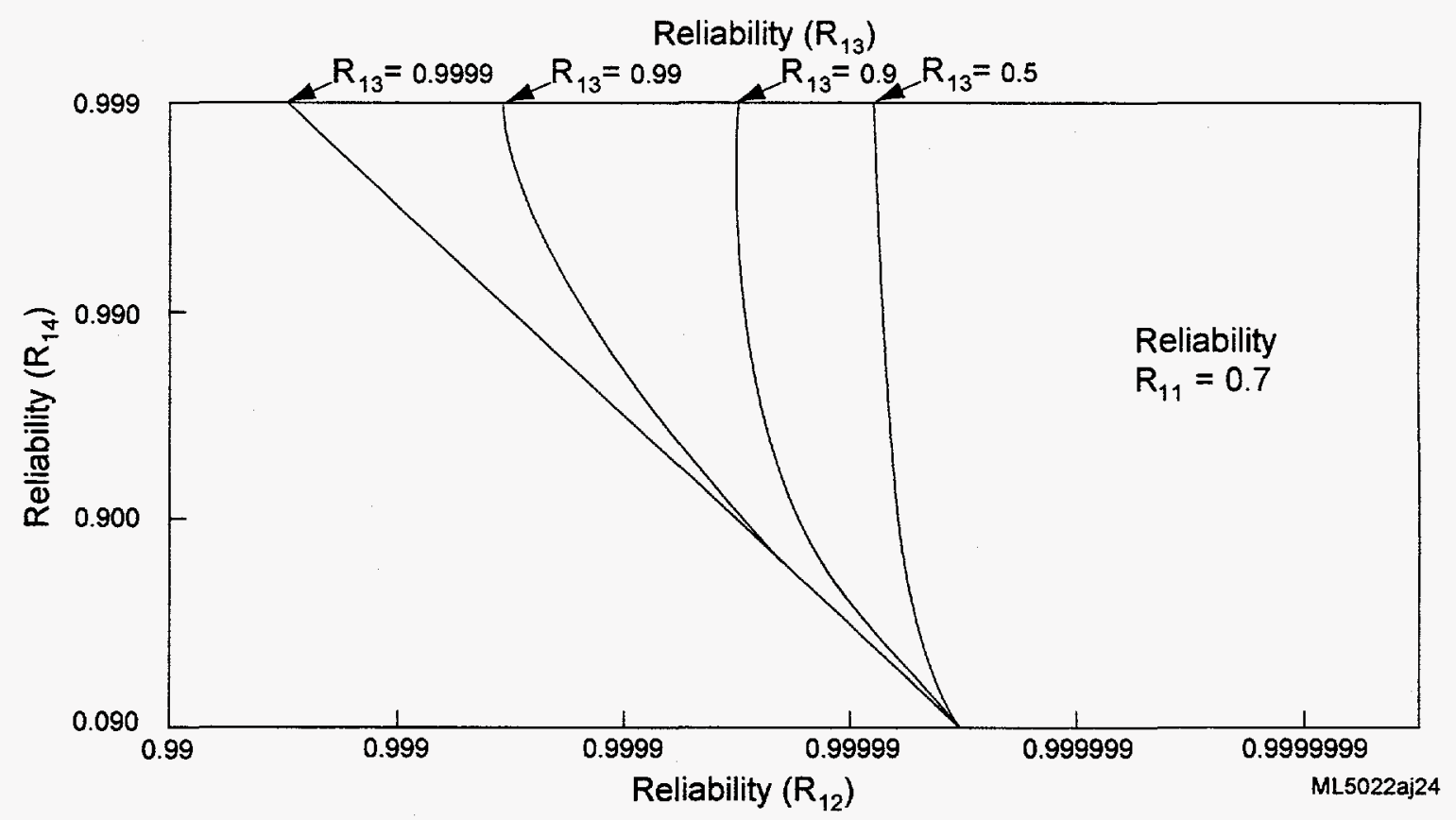

Figure 4-3a. Maintain waste container system reliability $\left(r_{i}=0.999999\right)$ based on $r_{i 1}=0.7$ and other indicated component reliabilities $\left(r_{i j}\right)$.

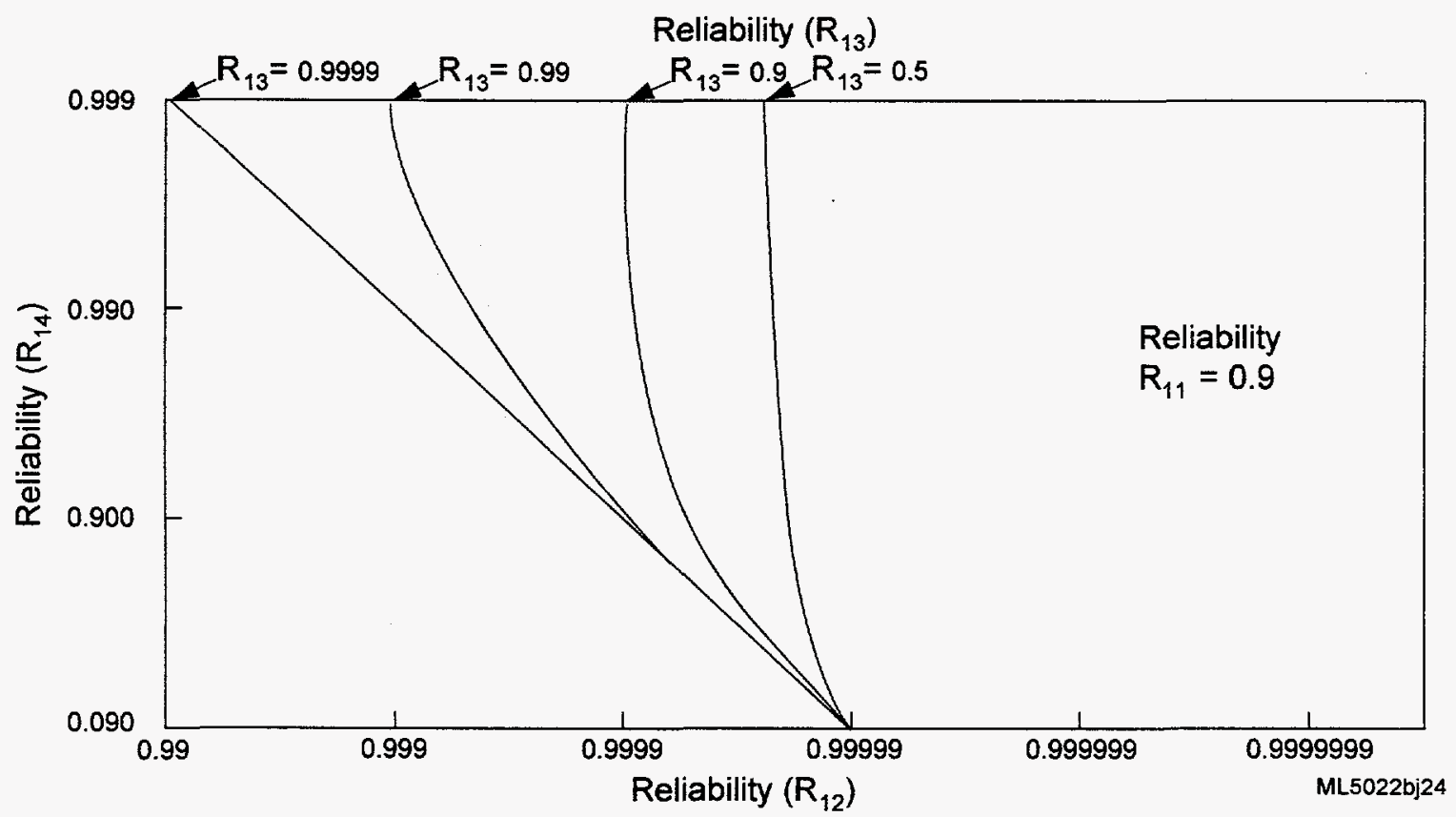

Figure 4-3b. Maintain waste container system reliability $\left(r_{i}=0.999999\right)$ based on $r_{i 1}=0.9$ and other indicated component reliabilities $\left(\mathrm{r}_{\mathrm{ij}}\right)$.

NOTE: For drum configuration $(i=1)$, and container component reliabilities [e.g., plastic bag $\left(r_{1 j=1}\right)$, liner $\left(r_{1 j=2}\right)$, inside corrosion $\left(r_{1 j=3}\right)$, outside corrosion $\left.\left(r_{1 j=4}\right)\right]$.

Figure 4-3. Container component reliabilities $\left(r_{j i}\right)$ to maintain waste system containment reliability at $r_{i}=0.999999$. 


\subsection{Sensitivity Analysis for Specified Component Reliability Conditions}

An initial Spaletta waste container analysis addressed the 28,500 drums (see Table 3-2) stored within the air support weather shields. These drums contain solid waste and have not been subjected to the aboveground, potentially harsher, earthen storage environment. The Spaletta analysis made the "... recommendation that the paint on the surfaces of the DOT 17C drums be disregarded in the evaluations of corrosion." Furthermore, "it [was] recommended that the plastic bags be disregarded when estimating TRU waste container lifetimes to provide a conservative estimate" (Spaletta 1990a). It is desirable to evaluate the reliability consequences of these recommendations.

The above drum containment system has the basic configuration factors that were listed in the objectives section and that correspond to Figure 4-2 for the system reliability model given by Equation (4-1). Consequently, it is possible to evaluate the sensitivity of the container system reliability to the Spaletta recommendations.

\subsection{Paint Failure}

There is a difference between individual container paint failure [i.e., $y_{1}=y_{2}=0$; see definitions for Equation (4-2)] and paint reliability equal to zero (i.e., $r_{\mathrm{y} 1=1}=r_{\mathrm{y} 2=1}=0$ ). The latter amounts to the condition that is recommended by Spaletta, and this appears to be an unnecessarily severe condition. Even if there is paint failure, it does not dictate a failure on each and every container system. Equation (4-5) shows the container system reliability model for paint reliability conditions equal to zero.

$$
\begin{aligned}
r_{1}= & r_{11}+\left(1-r_{11}\right) r_{12}+\left(1-r_{11}\right)\left(1-r_{12}\right) r_{13} r_{14} \\
& =r_{11}+\left(1-r_{11}\right) r_{12}+\left(1-r_{11}\right)\left(1-r_{12}\right)\left[r_{x 2}=1 \mid y 2=0\right]\left[r_{x 1=1 \mid y 1=0}\right]
\end{aligned}
$$

where

$$
\begin{aligned}
& r_{1}=\begin{array}{l}
\text { container system reliability for the } i=1 \text { type of container (DOT 17C 55-gal steel } \\
\text { drum) }
\end{array} \\
& r_{11}=\text { plastic bag component reliability } \\
& r_{12}=\quad \text { liner component reliability } \\
& r_{13}=\quad \begin{array}{l}
r_{x 2=1 \mid y 2=0}, r_{13} \text { is the inside container wall (noncorrosion) component reliability. } \\
r_{x 2=1 \mid y 2=0} \text { is the inside container wall (noncorrosion) component reliability given } \\
\text { failure of the inside paint [see Equation (4-3), with } \left.r_{\mathrm{y} 2=1}=0\right] \text { ]. }
\end{array} \\
& r_{14}=\begin{array}{l}
r_{\mathrm{x} 1=1 \mid \mathrm{y} 1=0}, \mathrm{r}_{14} \text { is outside container wall (noncorrosion) component reliability. } \\
r_{\mathrm{x} 1=1 \mid \mathrm{y} 1=0} \text { is the outside container wall (noncorrosion) component reliability } \\
\text { given failure of the outside paint [see Equation (4-2), with } \mathrm{r}_{\mathrm{y} 1=1}=0 \text { ]. }
\end{array}
\end{aligned}
$$




\subsection{Ignore Selected Components In The System}

Table 4-1 shows what happens with container system reliability sensitivity tradeoffs when $r_{11}$ and $r_{12}$ are ignored (i.e., $r_{11}=r_{12}=0$ ). These conditions lead to a reduced container sensitivity model as indicated in the column heading of Table 4-1. To achieve a given container system reliability under these conditions, each of the individual corrosion component reliabilities must be at least as high as the desired container system reliability. In other words, the system reliability cannot be any better than the least reliable of the components. Consequently, it is difficult to achieve the desired container system reliability since it depends so much on each of the individual component reliabilities.

Similarly, Table 4-2 shows container system reliability sensitivity tradeoffs for either of the following conditions:

- Ignore plastic bags $\left(r_{11}=0\right)$ and $50 \%$ liner reliability $\left(r_{12}=0.5\right)$

- Fifty percent plastic bag reliability $\left(r_{11}=0.5\right)$ and ignore liner reliability $\left(r_{12}=0\right)$.

Again, the reduced sensitivity model is indicated under the appropriate column heading in Table 4-2.

\subsection{Component Reliabilities}

The component reliabilities required to compute a value of container system reliability $\left(r_{i}\right)$ are summarized and defined by reference to the appropriate equation, as shown in Table 4-3. A methodology for component reliability value estimation is provided later. 
Table 4-1. Container system reliability sensitivity analysis for the conditions $r_{11}=r_{12}=0$.

\begin{tabular}{|c|c|c|c|c|c|c|c|}
\hline \multirow[t]{2}{*}{$\begin{array}{l}\text { Container system } \\
\text { reliability }\end{array}$} & \multicolumn{7}{|c|}{$\begin{array}{l}\text { Component reliabilities to achieve container system reliability } \\
\text { (constraints on system reliability model: } r_{11}=r_{12}=0 \text {, reduced model: } \\
\qquad r_{14}=r_{1} / r_{13} \text {, then } r_{13} \geq r_{1} \text { ) }\end{array}$} \\
\hline & & & & & & & \\
\hline Inside corrosion, $r_{13}$ & 0.999999 & 0.9999999 & & & & & \\
\hline Outside corrosion, $r_{14}$ & 1.0 & 0.9999991 & & & & & \\
\hline \multicolumn{8}{|l|}{$r_{1}=0.99999$} \\
\hline Inside corrosion, $r_{13}$ & 0.99999 & 0.999999 & & & & & \\
\hline Outside corrosion, $r_{14}$ & 1.0 & 0.999991 & & & & & \\
\hline \multicolumn{8}{|l|}{$r_{1}=0.9999$} \\
\hline Inside corrosion, $r_{13}$ & 0.9999 & 0.99999 & & & & & \\
\hline Outside corrosion, $\mathrm{r}_{14}$ & 1.0 & 0.99991 & & & & & \\
\hline \multicolumn{8}{|l|}{$r_{1}=0.999$} \\
\hline Inside corrosion, $\mathbf{r}_{13}$ & 0.999 & 0.9999 & & & & & \\
\hline Outside corrosion, $\mathrm{r}_{14}$ & 1.0 & 0.9991 & & & & & \\
\hline \multicolumn{8}{|l|}{$r_{1}=0.99$} \\
\hline Inside corrosion, $r_{13}$ & 0.99 & 0.999 & & & & & \\
\hline Outside corrosion, $\mathrm{r}_{14}$ & 1.0 & 0.991 & & & & & \\
\hline \multicolumn{8}{|l|}{$r_{1}=0.9$} \\
\hline Inside corrosion, $r_{13}$ & 0.9 & 0.99 & & & & & \\
\hline Outside corrosion, $\mathrm{r}_{14}$ & 1.0 & 0.991 & & & & & \\
\hline \multicolumn{8}{|l|}{$\mathrm{r}_{1}=0.8$} \\
\hline Inside corrosion, $\mathbf{r}_{13}$ & 0.8 & 0.9 & 0.95 & 0.99 & & & \\
\hline Outside corrosion, $\mathbf{r}_{14}$ & 1.0 & 0.8889 & 0.8421 & 0.8081 & & & \\
\hline \multicolumn{8}{|l|}{$r_{1}=0.7$} \\
\hline Inside corrosion, $r_{13}$ & 0.7 & 0.8 & 0.9 & 0.95 & 0.99 & & \\
\hline Outside corrosion, $r_{14}$ & 1.0 & 0.8750 & 0.7778 & 0.7368 & 0.7071 & & \\
\hline \multicolumn{8}{|l|}{$r_{1}=0.6$} \\
\hline Inside corrosion, $r_{13}$ & 0.6 & 0.7 & 0.8 & 0.9 & 0.95 & 0.99 & 1.00 \\
\hline Outside corrosion, $\mathrm{r}_{14}$ & 1.0 & 0.8571 & 0.7500 & 0.6667 & 0.6316 & 0.6061 & 0.6 \\
\hline \multicolumn{8}{|l|}{$r_{1}=0.5$} \\
\hline Inside corrosion, $\mathbf{r}_{13}$ & 0.5 & 0.6 & 0.7 & 0.8 & 0.9 & 0.95 & 0.99 \\
\hline Outside corrosion, $r_{14}$ & 1.0 & 0.8333 & 0.7143 & 0.6250 & 0.5556 & 0.5263 & 0.5051 \\
\hline
\end{tabular}


Table 4-2. Container system reliability sensitivity analysis for either the conditions $r_{11}=0$, and $r_{12}=0.5$ or $r_{11}=0.5$, and $r_{12}=0$.

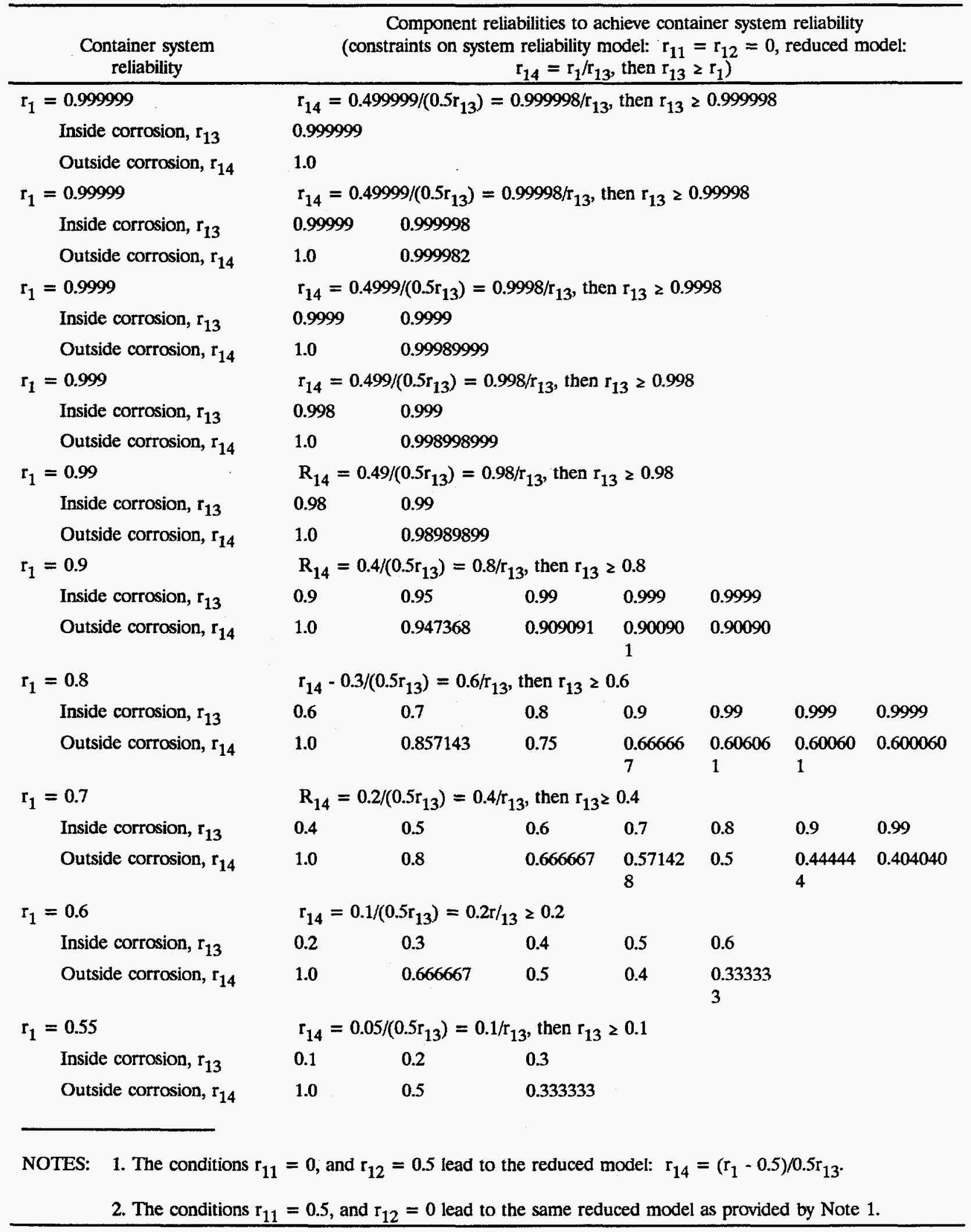


Table 4-3. Summary of component reliabilities.

\begin{tabular}{ccc}
\hline $\begin{array}{c}\text { Basic model } \\
\text { [Equation 4-1)] }\end{array}$ & $\begin{array}{c}\text { Outside paint model } \\
\text { [Equation (4-2)] }\end{array}$ & $\begin{array}{c}\text { Inside paint model } \\
\text { [Equation (4-3)] }\end{array}$ \\
\hline$r_{11}$ & $r_{x 1=1 \mid y 1=1}$ & $r_{x 2=1 \mid y 2=1}$ \\
$r_{12}$ & $r_{x 1=1 \mid y 1=0}$ & $r_{x 2=1 \mid y 2=0}$ \\
$r_{13}$ & $r_{y 1=1}$ & $r_{y 2=1}$ \\
$r_{14}$ & $r_{y 1=0}$ & $r_{\mathrm{y} 2=0}$ \\
\hline
\end{tabular}




\section{GENERAL SOLUTION FOR COMPONENT RELIABILITY AGING PROCESS}

\subsection{Introduction}

The previous sections of this report defined reliability models for waste containment systems in terms of component reliabilities $\left(r_{i j}\right)$. In the following sections, methodologies are developed to estimate the required component reliabilities. It is not only desirable but necessary to incorporate the capability to evaluate the potential degradation of component reliabilities due to aging into the methodologies.

For example, for the 55-gal drum containment system, the amount of drum corrosion depends on the length of storage time. Spaletta (1990a) provides various deterministic estimates of the amount of inside and outside drum wall corrosion over a projected drum life of 40 years. Spaletta $(1990 \mathrm{~b}, 1990 \mathrm{c})$ also considers corrosion rates for other types of container configuration systems by relating them to the corrosion rate for the drum container system.

A stochastic approach based on storage time to container failure was examined for application to RWMC waste containers. This approach by Chesnut (1991) defines container aging reliability using probability distributions (e.g., exponential) for multiple barrier container systems. Another stochastic approach by Duncan, et al. (1992) uses available container storage data to establish degradation rates. The rate parameters are used with Poisson probability distributions to project sample results to the number of container corrosion failures for the populations of containers being stored at the Hanford Site. These approaches merit further examination as candidates for potential application to RWMC waste container component reliability estimation.

It is important to be able to estimate container component aging reliabilities based on samples from populations of storage containers. In this regard, Plansky (1994) indicates that requirements for representative samples of containers have been identified for drums in the Certified and Segregated Waste Storage Building of the RWMC (see Appendix A of the Plansky report). Furthermore, the content code frequency distribution, code classifications, and number of containers to be selected from each class are given (see Appendix D of the Plansky report). Plansky states that approximately 30 containers are to be randomly sampled, if possible, from each class. The representative samples from the stored container populations are to be monitored for potential degradation and failure. Plansky indicates that containers will be added or released from the samples as more information is obtained from planned container monitoring and assessment. Adding or releasing containers results in storage time censoring as defined by Table 5-1. The censoring characteristics of the time data must be appropriately considered in order to develop methodologies to achieve satisfactory data analysis.

Implementation of the methodologies of this report to the container samples requires additional effort to define the waste container storage populations and to reconcile the data structure classes as indicated by Plansky (Appendix A and Appendix D) with the numbers (e.g., see Table 3-2) and types of waste container packaging configurations (e.g., Figure 4-1 shows the typical configuration for the 55-gal drum).

A classical approach to reliability estimation that is used in life testing is to draw a sample of component items and put them under test. Each and every item in the sample is then run until it fails. The exact time to failure is recorded for each item in the sample. This type of data 
Table 5-1. Types of life data (Nelson 1990).

\begin{tabular}{|c|c|}
\hline Data type & Description \\
\hline Complete data & Complete data arise if there is an exact failure time for each unit in the sample. \\
\hline Incomplete data & $\begin{array}{l}\text { Incomplete data arise if there is only partial information on failure times; that is, exact failure } \\
\text { times of some units are unknown. }\end{array}$ \\
\hline Censored & Life data are censored if the data must be analyzed before all units fail. \\
\hline \multirow[t]{5}{*}{$\begin{array}{l}\text { Censored on the } \\
\text { right }\end{array}$} & $\begin{array}{l}\text { Some units are unfailed and their failure times are known only to be beyond (i.e, to the right } \\
\text { of) their present running times. }\end{array}$ \\
\hline & $\begin{array}{l}\text { Unfailed units are called run-outs, survivors, removals, and suspensions. Such censored } \\
\text { data arise when some units are: }\end{array}$ \\
\hline & - $\quad$ Removed from test or service before they fail (e.g., removed from storage) \\
\hline & - Still running at the time of data analysis (e.g., continue in storage) \\
\hline & $\begin{array}{l}\text { - } \quad \text { Removed from test or service because they failed from an extraneous cause, } \\
\text { such as test equipment failure. }\end{array}$ \\
\hline Censored on the left & $\begin{array}{l}\text { Units for which failure times are known only to be before a certain time are said to be } \\
\text { censored on the left. }\end{array}$ \\
\hline $\begin{array}{l}\text { Singly censored on } \\
\text { the right }\end{array}$ & $\begin{array}{l}\text { If all unfailed units have a common running time and all failure times are earlier, the data are } \\
\text { said to be singly censored on the right. }\end{array}$ \\
\hline Singly censored & $\begin{array}{l}\text { Singly censored data arise when units are started together at test condition and the data are } \\
\text { analyzed before all units fail. }\end{array}$ \\
\hline $\begin{array}{l}\text { Singly time censored } \\
\text { (also called Type I } \\
\text { censored) }\end{array}$ & $\begin{array}{l}\text { The data are singly time censored if the censoring time is fixed; then, the number of failures in } \\
\text { that fixed time is random. }\end{array}$ \\
\hline $\begin{array}{l}\text { Singly failure } \\
\text { censored }\end{array}$ & $\begin{array}{l}\text { Data are singly failure censored if the test is stopped when a specified number of failures } \\
\text { occurs. The time to that fixed number of failures is random. }\end{array}$ \\
\hline \multirow[t]{3}{*}{$\begin{array}{l}\text { Multiply censored } \\
\text { (also, progressively, } \\
\text { hyper-, and } \\
\text { arbitrarily censored) }\end{array}$} & $\begin{array}{l}\text { Data censored on the right that have differing running times intermixed with the failure times. } \\
\text { Multiply censored data arise when units go on test at different times. Thus, they have different } \\
\text { running times when the data are recorded. Such data may be: }\end{array}$ \\
\hline & - $\quad$ Time censored-that is, running times differ from failure times \\
\hline & - Failure censored-that is running times equal to failure times. \\
\hline Competing modes & $\begin{array}{l}\text { A mix of competing failure modes occurs when sample units fail from different causes. Data } \\
\text { on a particular failure mode consist of the failure times of units failing by that mode. Such } \\
\text { data for a mode are multiply censored. }\end{array}$ \\
\hline Quantal-response & $\begin{array}{l}\text { Sometimes one knows only whether the failure time of a unit is before or after a certain time. } \\
\text { Each observation is either censored on the right or else on the left. Such life data arise if } \\
\text { each unit is inspected once to see if it has already failed or not. Such inspection data are } \\
\text { called quantal-response data, also called sensitivity, probit, binary, and all-or-nothing response } \\
\text { data. }\end{array}$ \\
\hline Interval & $\begin{array}{l}\text { When each unit is inspected for failure more than once, one knows only that a unit failed in } \\
\text { an interval between inspections, and this is so-called interval, grouped, or read-out data. Such } \\
\text { data can also contain right and left censored observations. }\end{array}$ \\
\hline Mixture & Data may also consist of a mixture of the above types of data. \\
\hline
\end{tabular}


corresponds to "complete data," as defined by Table 5-1. Incomplete data arise when the exact failure times of some units are unknown; this is a more typical situation. For example, it may not be possible to wait until every unit fails, especially for units with very long lives. Life data are censored if the data must be analyzed before all units fail. Waste storage container data must be censored because of the requirement to maintain container integrity for many years (e.g., as long as 40 years). Clearly, the analysis cannot be postponed until each waste container in the sample fails.

Furthermore, obtaining exact failure times is unjustified for RWMC waste storage containers. It would be very expensive to either require the instrumentation for each container in storage or very frequent (e.g., round-the-clock) surveillance and inspections on weekends and holidays. Such surveillance would entail frequent container inspections in order to measure and record exact storage failure times. Container stacking also makes it difficult to access individual containers for frequent inspections over many years of storage operation. It is inadvisable to perform experiments for collecting data that are considered unfeasible from a practical and economic standpoint.

Practical considerations lead to other types of life data (e.g., multiply censored and interval) as indicated by Table 5-1 and this, in turn, requires special analysis methodologies. However, analyses of such censored and interval data have much the same purposes as analyses of complete data; for example, estimation of reliability model parameters and product (e.g., waste container) life distribution and prediction of future observations.

Additional effort is required to adequately characterize the appropriate type of life data relative to RWMC container and storage limitations. Such effort is an essential key to developing statistically appropriate and practical procedures for estimating waste container system component reliabilities.

Section 5.2 provides a theoretical and practical basis for the further development of such procedures.

\subsection{General Solution for Component Reliability}

Consider a two-state irreversible stochastic process for which an aging item (e.g., waste storage container) is drawn randomly from a stated population (e.g., class of containers) at, say, a fixed sampling time. Assume that the sampling time can be related to pertinent container time variables (e.g., container waste storage time, container waste packing time). Eventually, it will be necessary to explicitly define the time variable but, for now, the variable will simply be called $t$. The nature of the time variable will be a key to establishing the type of data as indicated by Table 5-1.

The item selected at time point $\mathrm{t}$ can be either good or bad. When the item is found to be good (e.g., the container wall is not breached and meets container criteria), it is considered in good state $g$. When it is found bad (e.g., the container wall is breached), it is considered to be in bad state $b$. In subsequent report sections it will be necessary to explicitly define good and bad, and to develop methods for scoring good (success) and bad (failure) occurrences.

Initially, an aging item (i.e., storage container) will be assumed to be in the state $g$. Because of an aging effect, it will attain state $b$. Once it attains state $b$, it can never again return to state $g$. 
Let the function of time $R(t)$ be the probability that an aging item drawn randomly from a population of containers at time point $t$ is found to be in state $g$, and let $F(t)=1-R(t)$ be the probability that it is found to be in state $b$.

Let us assume that an aging item that is in state $g$ at time point $t$ attains state $b$ within a sufficiently small time interval $(\mathrm{t}, \mathrm{t}+\mathrm{h})$ with the probability $\lambda(\mathrm{t}) \mathrm{h}+\mathrm{o}(\mathrm{h})$, where $\lambda(\mathrm{t})$ may be termed the aging (e.g., corrosion deterioration) rate of the container at time $t$ and $o(h)$ is a notation for some function of $h$ satisfying $\lim _{h \rightarrow}[o(h) / h]=0$. Then,

$R(t+h)=R(t)[1-\lambda(t) h-o(h)]$

from which

$R^{\prime}(t)=d / d t[R(t)]=-\lambda(t) R(t)$

Using the initial condition $R(0)=1$ and the relationship for $R^{\prime}(t)$, then

$R(t)=e^{-\int_{0}^{t} \lambda(\omega) d \omega}$

where

$R(t)=$ reliability of a component (e.g., drum wall); that is, the probability that a component will remain functional to $t$ and will fail only after $t$

$\lambda(t)=$ failure rate

$\omega=$ dummy variable of integration

$\mathrm{t}=$ time (e.g., aging) variable.

The reliability of an item $R(t)$, as given by Equation (5-3), can be interpreted as the probability that an item will remain functional up to time point $t$ and will fail only after $t$. It can also be interpreted as probability that an aging item drawn randomly from a population class at time point $t$ will be found in state $g$ in the two-state irreversible process. These two interpretations of $R(t)$ are consistent and indeed not contradictory. Dubey (1965) provides additional background and insight into the derivation and interpretation of $R(t)$.

The reliability, $R(t)$, can represent either the waste container system as a whole or individual components, depending on an appropriate definition of "item" and the occurrence success/failure data specification.

For example, using the previous notation for the waste container system, let $r_{i}=R_{i}(t)$ for the ith waste container system. For the system components notation, let $r_{i j}=R_{i j}(t)$ where $i$ represents the ith type of waste container system and $j$ represents the individual components in the system. With this notation, $R_{i j}(t)$ can be used to estimate the component reliabilities in Equation (4-1). Estimating the individual component reliabilities and then using a model such as 
Equation (4-1) for the system is preferred because it can be more useful and accurate, especially if there is interest in highly reliable waste container systems.

With a suitable notation modification, namely $r_{x \mid y}=R_{i j}(t \mid y)$, the conditional reliability probabilities (i.e., reliability given y) required by Equations (4-2) and (4-3) can be determined. Appendix A provides a derivation of the required relationships in terms of the basic occurrence variables. Appendix B provides a derivation of $R(t \mid y)$. These relationships now provide a basis for estimating the required component reliabilities.

Let the value $R_{i j}(t \mid y)$ be the probability that an aging item (i.e., for container system $i$ and container component $\mathrm{j}$ ) as drawn randomly from a population of containers at time point $t$ is found to be in state $g$, and let $F_{i j}(t \mid y)=1-R_{i j}(t \mid y)$ be the probability that it is found to be in state $b$.

Note that by choosing $\lambda(t)$ appropriately, we can get the suitable expression for $R(t)$ and, whenever necessary, for $F^{\prime}(t)$. The selection of $\lambda(t)$ for diverse applications will be considered later in this report.

\subsection{Objectives of Component Reliability Model}

The reliability of a waste container system is expressed by Equation (4-1) in terms of the reliabilities of the components. Therefore, to obtain an estimate of waste container system reliability, it is necessary to estimate the reliability of each component in the model. However, the reliability of some of the components may depend on enhancement variables (e.g., paint); for example, see Equations (4-2) and (4-3) respectively. Consequently, it is necessary to generalize the component reliability model to account for enhancement variables in the estimation of component reliability.

An initial step in the estimation of component reliability is the mathematical derivation of the "true" (population) component reliability. Hence, an objective is to derive a mathematical model for the "true" component reliability that considers the following three key variables:

An attribute (i.e., success/failure) variable

A continuous (e.g., age) variable

A container enhancement (e.g., container paint) variable.

This report presents a component reliability model that considers the above three variables and, hence, represents a unified approach for determining component reliability.

In order to make effective use of the component model described herein, it will be necessary to develop procedures for estimating "true" component reliability on the basis of sample data. Several such estimating procedures are referred to in this report, but are not considered in detail at the present time. 


\subsection{Component Reliability Model Assumptions}

The component reliability model, as developed in this report, enables reliability to be expressed as a function of three basic variables. The first variable $\left(\mathrm{x}_{\mathrm{k}}\right)$ is Bernoulli and takes the value of 0 if the component item (e.g., container wall) is found to be defective (i.e., bad), and is 1 otherwise. The second variable (y) is also Bernoulli and takes the value of 0 if the enhancement component item (e.g., container paint) is found to be defective, and is 1 otherwise. The third variable ( $t$ ) may represent the age of the component or some other meaningful variable that is important in waste container component reliability assessment, and is one of the major concerns of this report. follows:

The assumptions surrounding the derivation of the component reliability model are as

- The probability of $x$ (where $x=\Sigma x_{k}$ ), given $y$ and $t$, is binomially distributed since

- The success/failure outcome of the kth component $\left(x_{k}\right)$, given $y$ and $t$, is independent of the outcome of other components

- The probability of $x_{k}$, given $y$ and $t$, is constant for every component of a particular type

- The probability of success variable $(y=1)$ is a Bernoulli trial with assigned weight parameter $P$; let $P=r_{y 1=1}$ be the reliability of the paint

- The probability of $t$ is uniformly distributed for $t$ in the interval $a$ to $b$.

The first assumption appears to be generally applicable (for a component type) as long as component reliability can be expressed in terms of the three variables $x_{k}, y$, and $t$. The second assumption depends on adequate estimation of the reliability of the enhancement variable (e.g., paint). The third assumption should be further evaluated after the type of component and $t$ have been more explicitly defined for a particular set of data. For additional detail concerning the meaning of these assumptions, see Appendix A.

The component reliability model that includes the enhancement variable is developed in detail in Appendices A and B, and is summarized in following sections.

\subsection{Model for Reliability $\left(r_{i j}\right)$ of the ijth Component}

The model for determining the reliability of the jth component within the ith type waste container system is expressed as follows:

$r_{i j}=\frac{1}{b} \sum_{y=0}^{1} p^{y}(1-p)^{1-y} \int_{0}^{b} R(t \mid y) d t$ 
where

$$
\begin{aligned}
& \mathrm{r}_{\mathrm{ij}} \quad=\text { the reliability of the jth component within the ith waste container system } \\
& \mathrm{b} \\
& \mathrm{p}=\mathrm{r}_{\mathrm{y}=1}=\text { the upper limit for } \mathrm{t} \\
& \mathrm{y} \quad=\quad \begin{array}{l}
1 \text { for nonfailure of the enhancement variable (e.g., container paint) } \\
0 \text { for failure of the enhancement variable (e.g., container paint) }
\end{array} \\
& \mathrm{R}(\mathrm{t} \mid \mathrm{y}) \quad=\text { the reliability of a component (e.g., drum wall) given y. }
\end{aligned}
$$

The reliability of the drum wall component is given by $R(t \mid y)$.

$R(t \mid y)=e^{-\int_{0}^{t} \lambda(\omega) y d \omega}$

where

$$
\begin{aligned}
& \mathrm{R}(\mathrm{t} \mid \mathrm{y})=\quad \begin{array}{l}
\text { the reliability of a component (e.g., drum wall) given } \mathrm{y} ; \text { that is, the } \\
\text { probability that a component will remain functional to } t \text { and will fail only } \\
\text { after } \mathrm{t}
\end{array} \\
& \lambda(\mathrm{t})_{\mathrm{y}}=\text { the failure rate, given } \mathrm{y} \\
& \omega \quad=\quad \text { a dummy variable of integration. }
\end{aligned}
$$

The model [Equation (5-4)] is versatile because of the latitude allowed in the specification of the failure rate in Equation (5-5). If the failure rate, $\lambda(t)_{y}$, is known, $R(t \mid y)$ can be expressed as a particular function of $t$ which, when substituted into Equation (5-4), yields a value for $r_{i j}$, providing that $P$ and $b$ are given. Therefore, the model [Equation 5-5)] is not limited to a single functional form, but can be expressed in other forms depending on the failure rate exhibited by the continuous variable $t$. To illustrate this versatility, the functional form for $r_{i j}$ will be indicated for two particular failure rates as follows:

$$
\lambda(t)_{y}=\frac{1}{\theta_{y}}
$$

and

$$
\lambda(\mathrm{t})_{\mathrm{y}}=\frac{1}{\theta_{\mathrm{y}}} \mathrm{t}^{\left(\mathrm{m}_{\mathrm{y}}-1\right)}
$$


for $\lambda(t)_{y^{*}}$

Note that $\lambda(t)_{y}$ is not limited to the above possibilities, although these are common forms

\subsubsection{Exponential Reliability Versus $t$}

If the failure rate, $\lambda(t)_{y}$, is a constant versus $t$ as given by Equation (5-6), then

$R(t \mid y)=e^{-\frac{t}{\theta_{y}}}$

which indicates that $R(t \mid y)$ is exponentially distributed. (The parameter $\theta_{y}$ is commonly called the mean time between failure.)

If equation (5-8) is substituted into Equation (5-4), then

$r_{i j}=\frac{1}{b} \sum_{y=0}^{1} P^{y}(1-P)^{1-y}\left(\theta_{y}\right)\left(1-e^{-\frac{b}{\theta_{y}}}\right)$

Equation (5-9) should be used to determine the reliability of components that have constant failure rate and, hence, have a reliability that decreases exponentially with $t$.

\subsubsection{Weibull Reliability Versus $t$}

If the failure rate, $\lambda(t)$, is given by Equation (5-7), then the reliability $R(t \mid y)$ follows the Weibull distribution (Weibull 1951). That is

$R(t \mid y)=e^{-\frac{1}{\theta_{y}}\left(m_{y}\right)}$

where

$\mathrm{m}_{\mathrm{y}}=$ the shape or slope parameter (e.g., common notation is $\beta$ )

$\theta_{\mathrm{y}}=$ the scale parameter.

The two-parameter Weibull has greater generality than the single parameter exponential. Note that for the special case of $m_{y}=\beta=1$, the Weibull, Equation (5-10), reduces to the exponential.

Substituting Equation (5-10) into Equation (5-4) gives

$r_{i j}=\frac{1}{b} \sum_{y=0}^{1} P^{y}(1-P)^{(1-y)} \int_{0}^{b} e^{-\frac{1}{\theta_{y}} t^{(m y)}} d t$ 


\subsubsection{Summary}

Section 5 presents a method for obtaining component reliability, where each component is considered from the standpoint of the following key variables:

- An attribute (i.e., success/failure) variable

- A continuous (such as age) variable

- An enhancement (e.g., paint) variable.

In Equation (5-4), the attribute and continuous variables are considered in the derivative of $\mathbf{R}(\mathbf{t} \mid \mathrm{y})$ [see Equation (A-6) in Appendix A and Appendix B]. The enhancement (e.g., paint) variable is considered in the specification of $P$ in Equation (5-4).

Equation (5-4), therefore, represents a general reliability model for the ijth component since its specific functional form is dependent on $R(t \mid y)$, which in turn depends on the failure rate $\lambda(t)_{y}$. The functional form of $r_{i j}$ was indicated for two particular failure rates, Equations (5-6) and (5-7). These particular failure rates were selected because of their wide applicability in reliability assessment. It should be noted, however, that $\lambda(t))_{y}$ is not limited to the above two situations and, in fact, Dubey (1965) provides several other failure rates that can be considered in diverse applications.

Note that the reliability model [Equation (5-4)] can be further generalized as indicated by Englehardt ${ }^{\mathrm{a}}$ and given by Equation (5-12).

$$
r_{i j}=\sum_{y=0}^{1} P^{y}(1-P)^{1-y} \int_{0}^{\infty} R(t \mid y)_{k} f(t \mid y) d t
$$

In the case where $T$ is uniform on the interval $[0, b]$ then $f(t \mid y)$ is given by Equation (A-7) of Appendix A and Equation (5-12) reduces to Equation (A-13) of Appendix A, and likewise Equation (5-4). If $f(t \mid y)=2 t / b^{2}$ in the interval $0<t<b$, then $T$ would be triangular rather than uniform and Equation (5-12) could be modified to reflect this situation. Furthermore, distributions of $\mathbf{T}$ other than the uniform and triangular might also be appropriately considered in Equation (5-12).

a. Max Englehardt, private communication with Karl L. Smith, Lockheed Idaho Technologies Company, concerning review of the report, Reliability Evaluation Methodologies for Ensuring Container Integrity of Stored Transuranic (TRU) Waste, March 7, 1995. 


\section{IMPLEMENTATION OF THE COMPONENT RELIABILITY MODEL}

\subsection{Definition of Variables}

Since historical data are available for INEL RWMC waste container storage, an initial step in the implementation of component reliability models would be to evaluate existing data with respect to "key" variables. The purpose of the evaluation would be to define the key variables for each type of waste container. For example, Figure 4-1 indicates that there are six key variables for the waste storage drum. The scoring outcomes resulting from an examination of a particular stored waste container (e.g., drum) could be represented by defining a Bernoulli trial scoring specification of 0 or 1 for each of six dichotomous variables, 0 representing a "failure" and 1 representing a "success" (i.e., suspension). Consequently, there could be $2^{6}=64$ possible scoring outcome combinations for the six variables. For each variable, it would be necessary to develop a definition of what constitutes a failure. It would also be necessary to specify the associated time (t) variable (e.g., storage time).

Using the component reliability models of this report, some of the six variables of Figure 4-1 are grouped with respect to outside or inside components. Such groupings include an attribute variable $\left(x_{k}\right)$, (i.e., success or failure), a continuous variable ( $\left.t\right)$, and an enhancement (e.g, paint) attribute (i.e., success or failure) variable (y).

\subsection{Sample Estimates Of Reliability}

The component reliability model given by Equation (5-4) gives the "true" or population reliability. However, from a practical standpoint, the population value is unattainable, since it would require testing every component in the population. For this reason, it is necessary to estimate $r_{i j}$ using probability sampling (Cochran 1963). Ideally, the probability sampling procedure should be developed before the data sample is taken. However, this ideal is unattainable when the data have already been collected. In such a case, it is necessary to investigate the approximate compatibility of the available data with respect to several sampling methods and, thereby, determine an appropriate method of estimation. For example, several possible procedures for obtaining sample estimates are available (Dubey 1965; Nelson 1990) depending on the type of data (see Table 5-1).

Before Equation (5-4) can be used to obtain component reliability, it is necessary to determine the functional form of $R(t \mid y)$-that is, is $R(t \mid y)$ a linear function, a normal function, an exponential function, Weibull function, etc.? In determining the functional form of $R(t \mid y)$, it was previously stated that the failure rate, $\lambda(t)_{y}$, must be specified. This might be done on the basis of prior testing or engineering expertise. Consequently, assuming that an estimate of the failure rate can be obtained, substitution into Equation (5-5) produces an estimate of $R(t \mid y)$.

An alternate method of determining the functional form of $R(t \mid y)$ is available (Dubey 1965). This method may be used when the structure of the data prevents evaluation of $\lambda(t)_{y}$ According to this method, the functional form of $\mathrm{R}(\mathrm{t} / \mathrm{y})$ is determined on the basis of point estimates of $R(t \mid y)$, which are given by 
$\hat{R}(t \mid y)=\frac{g(t \mid y)}{n(t \mid y)}$

where

$$
\begin{aligned}
& \mathbf{g}(\mathrm{t} \mid \mathrm{y}) \quad=\text { the number of nondefective components at } \mathrm{t} \text { given } \mathrm{y} \\
& \mathbf{n}(\mathrm{t} \mid \mathrm{y}) \quad=\text { the total number of components in the sample at } \mathrm{t} \text { given } \mathrm{y} .
\end{aligned}
$$

The functional form of $R(t \mid y)$ can be evaluated based on the point estimates calculated in Equation (5-13). A functional form for $R(t \mid y)$ can be assumed (normal, linear, etc.) and estimates of the function parameters can be obtained. Then, using appropriate goodness-of-fit tests the compatibility of the observed distribution function [i.e., point estimates of $R(t \mid y)$ ] with the assumed distribution function can be assessed. The hypothetical example in Section 6.3 illustrates this alternate method.

\subsection{Hypothetical Example}

Consider the hypothetical data given in Table 6-1. The variable y identifies the data enhancement (e.g., paint) variable outcome, the variable $t$ is the component age in months, $n(t \mid y)$ is the sample size, and $\mathrm{g}(\mathrm{t} / \mathrm{y})$ is the number of successes. Suppose that this type of component must operate for $b=100$ months with good reliability. A sample estimate of the reliability of the component is required. Note that there is no particular relationship between the sample sizes as tabulated in Table 6-1.

Table 6-1. Hypothetical data for sample size $[n(t \mid y)]$ and number of successes $[g(t \mid y)]$ versus component age $(t)$ in months.

\begin{tabular}{rllccccc}
\hline \multicolumn{3}{c}{ Paint nonfailure $(\mathrm{y}=0)$} & \multicolumn{5}{c}{ Paint failure $(\mathrm{y}=1)$} \\
\hline $0 \leq \mathrm{T} \leq \mathrm{t}$ & $\mathrm{n}(\mathrm{t} \mid \mathrm{y})$ & $\mathrm{g}(\mathrm{t} \mid \mathrm{y})$ & $\mathrm{b}(\mathrm{t} \mid \mathrm{y})$ & $0 \leq \mathrm{T} \leq \mathrm{t}$ & $\mathrm{n}(\mathrm{t} \mid \mathrm{y})$ & $\mathrm{g}(\mathrm{t} \mid \mathrm{y})$ & $\mathrm{b}(\mathrm{t} \mid \mathrm{y})$ \\
\hline 0 & 500 & 500 & 0 & 5 & 200 & 198 & 2 \\
10 & 340 & 337 & 3 & 20 & 280 & 269 & 11 \\
25 & 650 & 634 & 16 & 25 & 400 & 380 & 20 \\
30 & 190 & 184 & 6 & 35 & 320 & 298 & 22 \\
50 & 200 & 190 & 10 & 50 & 600 & 543 & 57 \\
55 & 150 & 142 & 8 & 55 & 550 & 493 & 57 \\
60 & 420 & 396 & 24 & 70 & 350 & 304 & 46 \\
75 & 160 & 148 & 12 & 85 & 150 & 127 & 23 \\
85 & 600 & 551 & 49 & - & - & - & - \\
90 & 300 & 274 & 26 & - & - & - & - \\
100 & 380 & 344 & 36 & - & - & - & - \\
\hline
\end{tabular}


For the various values given in Table 6-1, sample estimates of both $R(t \mid y=0)$ and $R(t \mid y=1)$ were calculated using Equation (6-1), and are tabulated in Table 6-2. The following functional forms for $R(t \mid y)$ will be assumed:

$R(t \mid y)=e^{-\frac{t}{\theta_{y}}}$

and

$R(t \mid y)=a_{y}+b_{y} t$

The data tabulated in Table 6-2 will be used to estimate the parameters in Equations (6-2) and (6-3).

\subsubsection{Illustration for Exponential $R(t \mid y)$}

For $R(t \mid y)$ given by Equation (6-2), a least squares estimate of $\theta_{y}$ is given by Equation (6-4).

$$
\hat{\theta}_{y}=\frac{-\sum t_{i}^{2}}{\sum\left[\ln \hat{R}\left(t_{i} \mid y\right)\right] t_{i}} .
$$

Table 6-2. Estimated $\mathrm{R}(\mathrm{t} \mid \mathrm{y})$ using Equation (5-11) and the data from Table 6-1.

\begin{tabular}{|c|c|c|c|c|c|}
\hline \multicolumn{3}{|c|}{ Paint nonfailure $(y=1)$} & \multicolumn{3}{|c|}{ Paint failure $(y=0)$} \\
\hline $0 \leq \mathrm{T} \leq \mathrm{t}$ & $\hat{R}(t \mid y=1)$ & $\hat{\mathrm{F}}(\mathrm{t} \mid \mathrm{y}=1)$ & $0 \leq \mathrm{T} \leq \mathrm{t}$ & $\hat{R}(t \mid y=0)$ & $\hat{F}(t \mid y=0)$ \\
\hline 0 & 1.000 & 0.000 & 5 & 0.990 & 0.010 \\
\hline 10 & 0.991 & 0.009 & 20 & 0.961 & 0.039 \\
\hline 25 & 0.975 & 0.025 & 25 & 0.950 & 0.050 \\
\hline 30 & 0.968 & 0.032 & 35 & 0.931 & 0.069 \\
\hline 50 & 0.950 & 0.050 & 50 & 0.905 & 0.095 \\
\hline 55 & 0.947 & 0.053 & 55 & 0.896 & 0.104 \\
\hline 60 & 0.943 & 0.057 & 70 & 0.869 & 0.131 \\
\hline 75 & 0.925 & 0.075 & 85 & 0.847 & 0.153 \\
\hline 85 & 0.918 & 0.082 & - & - & - \\
\hline 90 & 0.913 & 0.087 & - & - & - \\
\hline 100 & 0.905 & 0.095 & - & - & - \\
\hline
\end{tabular}


Using Equation (6-4) and the data from Table 6-2, estimated $\theta=991$ for $y=1$, and estimated $\theta=503$ for $y=0$. Substituting the estimates of $\theta_{y}$ into Equation (6-2) gives estimates of $R(t \mid y=0)$ and $R(t \mid y=1)$ versus $t$.

Arbitrarily assume a paint reliability $(P=0.6)$ for the nonfailed paint data. For $b=100$, estimated $\theta_{1}=991$ and estimated $\theta_{0}=503$, Equation (6-2) can be used to obtain the following estimate of component reliability $\left(\mathrm{r}_{\mathrm{ij}}\right)$ :

$\hat{\mathrm{r}}_{\mathrm{ij}}=0.9335$.

\subsubsection{Illustration For Linear $\mathbf{R}(\mathbf{t} \mid \mathbf{y})$}

If $R(t \mid y)$ is assumed to be a linear function of $t$, substituting Equation (6-3) into the component reliability model [Equation (5-4)] gives the following expression for $r_{\mathrm{ij}}$ :

$r_{i j}=\sum_{y=0}^{1} P^{y}(1-P)^{1-y}\left(a_{y}+\frac{1}{2} b_{y} b\right)$

If the functional form for $R(t \mid y)$ is given by Equation (6-3), then least square estimates of $a_{y}$ and $b_{y}$ for the data in Table 6-2 are given as follows:

For $\mathrm{y}=1$

estimated $a_{1}=0.99911$, and estimated $b_{1}=-0.0009573$

and

For $\mathrm{y}=0$ :

estimated $a_{0}=0.99607$, and estimated $b_{0}=-0.001796$

Estimates of $R(t \mid y)$ versus $t$ can be obtained by substituting the estimates, as given by Equations (6-7) and (6-8) into Equation (6-3).

Substitution of $b=100, P=0.6$, and the estimates given by Equations (6-7) and (6-8) into Equation (6-4) gives

$\hat{\mathbf{r}}_{\mathrm{ij}}=0.9933$.

\subsubsection{Comparison Summary}

Equations (6-5) and (6-9) give estimates that are similar, although the functional forms assumed for $R(t \mid y)$, [i.e., Equations (6-2) and (6-3)] are very different. Actually, the similarity between the estimates of $r_{i j}$ is not very surprising since the estimated $R(t \mid y)$ are approximately linear over the short time interval.

The hypothetical data tabulated in Table 6-1 were generated using an exponential function for $R(t \mid y)$ with true $\theta_{1}=1,000$ and $\theta_{0}=500$. The discrepancy between the true values of $\theta_{y}$ 
and the estimates $\theta_{1}=991$ and $\theta_{0}=503$ is the result of rounding the product $[\mathrm{n}(\mathrm{t} \mid \mathrm{y}) \mathrm{R}(\mathrm{t} \mid \mathrm{y})]$ to the nearest integer when obtaining the values of $\mathrm{g}(\mathrm{t} \mid \mathrm{y})$ as tabulated in Table 6-2.

It is also informative to graph the point estimate data from Table 6-2 on Weibull probability paper as indicated by Figure 6-1. These data lie on the straight lines indicated by Figure 6-1.

On Weibull probability paper, a Weibull function graphs as a straight line. Furthermore, an exponential function also graphs as a straight line, since it is a special case of a Weibull with the slope parameter $(\beta=1)$. Consequently, graphing point estimates on Weibull probability paper provides a method for evaluating the functional nature of the data and can enhance model implementation. Weibull analysis techniques (Abernathy et al. 1983; Abernathy computer program $)^{b}$ are available to perform graphing and parameter estimation.

b. Weibullsmith computer program, Dr. R. B. Abernathy, Technical Advisor, Fulton Findings, 1251 W. Sepulveda Blvd., Suite 800, Torrance, California 90502. 


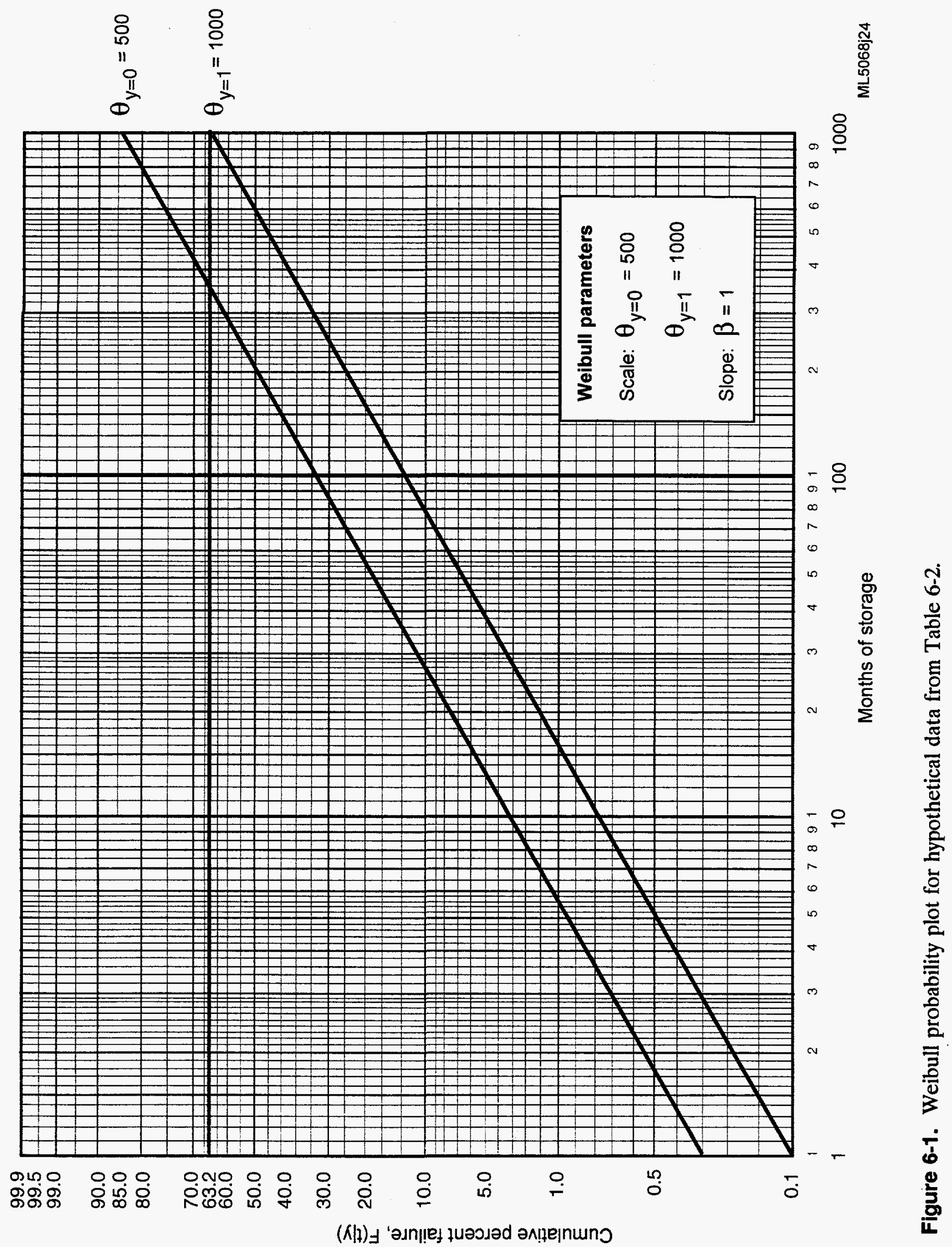




\section{REFERENCES}

Abernathy, R. B., J. E. Breneman, C. H. Medlin, G. L. Reinman, 1983, Weibull Analysis Handbook, AFWAL-TR-83-2079, Pratt \& Whitney Aircraft, Government Products Division, United Technologies Corporation, November.

Bradford, Richard M., 1993, The Role of Multiple Barriers in Assuring Waste Package Reliability, UCRL-ID-114739, Yucca Mountain Project, Systems Research Group, Lawrence Livermore National Laboratory, August.

Chesnut, Dwayne A., 1991, Demands Placed on Waste Package Performance Testing and Modeling by Some General Results of Reliability Analysis, September.

Cochran, William G., 1963, Sampling Techniques, John Wiley and Sons, Inc.

Dubey, S. D., 1965, Asymptotic Properties of Several Estimators of Weibull Parameters, Technometrics, Volume 7, No. 3, August.

Duncan, D. R., D. A. Burbank, B. C. Anderson, and J. A. Demiter, 1992, Application of Service Examinations to Transuranic Waste Container Integrity at the Hanford Site, WHC-SA-1450FP, Westinghouse Hanford Company, Richland, Washington, October.

EG\&G Idaho, 1994, Safety Analysis Report for the Radioactive Waste Management Complex at the Idaho National Engineering Laboratory, EGG-WM-10881, EG\&G Idaho, Inc., May.

Nelson, Wayne, 1990, Accelerated Testing, Statistical Models, Test Plans, and Data Analyses, John Wiley \& Sons, New York.

Parzen, Emanuel, 1960, Modern Probability Theory and Its Applications, John Wiley \& Sons, Inc.

Plansky, Lee E., 1994, Contact-Handled Transuranic Container Integrity Program Fiscal Year 1994 Work Summary, September 23.

Spaletta, H. W., 1990a, letter to L. L. Clements, Jr., "Stored Transuranic (TRU) Waste Container Integrity Evaluation," HWS-1-90, interoffice correspondence, EG\&G Idaho, Inc., February 23.

Spaletta, H. W., 1990b, letter to T. L. Clements, Jr., "Stored Transuranic (TRU) Waste Container Evaluation," HWS-3-90, interoffice correspondence, EG\&G Idaho, Inc., April 11.

Spaletta, H. W., 1990c, letter to T. L. Clements, Jr., "Stored Transuranic (TRU) Waste Container Evaluation," HWS-19-90, interoffice correspondence, EG\&G Idaho, Inc., September 25.

Weibull, Waloddi, 1951, "A Statistical Distribution Function of Wide Applicability," Journal of Applied Mechanics, September. 


\section{Appendix A}

\section{Model Derivation}

A-1 
A-2 


\section{Appendix A}

\section{Model Derivation}

\section{A-1. INTRODUCTION}

Initially, it is necessary to define reliability for a single component of a specified type. The definition of reliability for a single component must then be extended to the population of $\mathrm{N}$ components. The model given by Equation (5-4) is based on a definition of reliability for each component in a population of $\mathrm{N}$ components of a specified type. The essence of the derivation of the reliability models for both a single component and $\mathrm{N}$ components can be summarized as follows:

- For a single component of a specified type

- For the kth component, define a dichotomous random variable $X_{k}$. Also, define a dichotomous random variable, $\mathrm{Y}$, and continuous random variable, $\mathrm{T}$.

- Define conditional reliability of the kth component as the expected value of $x_{k}$ given $y$ and $t, E\left(x_{k} \mid y, t\right)$, and the reliability of the kth component as the expected value of $x_{k}, E\left(x_{k}\right)$.

- Before the expected value of $x_{k}$ can be determined, it is necessary to obtain the joint probability density, $f\left(x_{k}, y, t\right)$. An expression for the joint density will be derived through the use of conditional probability. It should be noted that $X_{k}$ and $Y$ are discrete random variables, while $T$ is a continuous random variable. This mixture of discrete and continuous random variables introduces additional complexity in the derivation of the joint density.

- $\quad$ For $\mathrm{N}$ components of a specified type

- Dichotomous random variables, $X_{k}$, are defined for $k=1,2, \ldots, N$, where $N$ is the number of components of the specified type in the population. In addition, a random variable, $X=\sum_{k=1}^{N} X_{k}$, is also defined.

- Define conditional reliability of the $N$ components as the expected value of $\bar{x}$ given $y$ and $t, E(\bar{x} \mid y, t)$, and the component reliability $\left(r_{i j}\right)$ as the expected value of $\bar{x}$, $E(\bar{x})$, where

$\overline{\mathrm{x}}=\frac{1}{\mathrm{~N}} \sum_{\mathrm{k}=1}^{\mathrm{N}} \mathrm{x}_{\mathrm{k}}$

- In order to determine the expected value of $\bar{x}$, it is necessary to define the joint probability density functions, $f\left(x_{1}, x_{2}, \ldots x_{N}, y, t\right)$ and $f(x, y, t)$. 


\section{A-2. RELIABILITY DERIVATION FOR A SINGLE COMPONENT OF A GIVEN TYPE}

For the kth component in the population of components of the same type, define a random variable $X_{k}$, which takes the values

$x_{k}=\left\{\begin{array}{l}0 \text { if the } k \text { th component is defective, and } \\ 1 \text { if the } k \text { th component is nondefective. }\end{array}\right.$

In addition, define a random variable $\mathrm{Y}$, which takes the values

$y=\left\{\begin{array}{l}0 \text { if the enhancement component is defective, and } \\ 1 \text { if the enhancement component is nondefective. }\end{array}\right.$

The variable $\mathrm{T}$ is a continuous random variable. For example, $\mathrm{T}$ may be the age of the component.

Probability statements can be made using the above random variables $\left(\mathrm{X}_{\mathrm{k}}, \mathrm{Y}, \mathrm{T}\right)$. For example, the joint probability that the kth component is nondefective $\left(x_{k}=1\right)$, the enhancement is nondefective $(y=1)$, and has a $T$ in the interval $0 \leq T \leq t$, can be defined as

$\operatorname{Pr}\left(x_{k}=1, y=1,0 \leq T \leq t\right)=\int_{0}^{t} f\left(x_{k}=1, y=1, z\right) d z^{a}$

where $f\left(x_{k}, y, t\right)$ is a joint probability density function that involves both discrete and continuous random variables.

Integration of Equation (A-2) is required since probabilities computed using continuous random variables require integration of the probability density function. On the other hand, probabilities using discrete random variables are given directly by the probability density function.

Using the definition of conditional probability (Mood and Graybill 1963), the joint probability density can be expressed as follows:

$$
\begin{aligned}
f\left(x_{k}, y, t\right) & =f\left(x_{k} \mid y, t\right) f(y, t) \\
& =f\left(x_{k} \mid y, t\right) f(t \mid y) f(y)
\end{aligned}
$$

where

$$
f\left(x_{k} \mid y, t\right)=\text { the probability density of } x_{k} \text { given } y \text { and } t
$$

a. $\mathbf{z}$ is a dummy variable of integration. 
$f(t \mid y) \quad=\quad$ the probability density of $t$ given $y$

$f(y)=$ the marginal probability of $y$.

The function $f\left(x_{k} \mid y, t\right)$ is the conditional probability of $x_{k}$ given $y$ and $t$, since $x_{k}$ is a discrete random variable. On the other hand, since $t$ is a continuous random variable, the function $f(t \mid y)$ becomes a probability conditioned on $y$ when the function is integrated. That is,

$\operatorname{Pr}\left(0 \leq \mathrm{T} \leq \mathrm{t} \mid \mathrm{y}=\int_{0}^{t} \mathrm{f}(\mathrm{z} \mid \mathrm{y}) \mathrm{dz}\right.$

The marginal probability, $\mathrm{f}(\mathrm{y})$, in Equation (A-3) is given by the following equation:

$f(y)=\sum_{x_{k}=0}^{1} \int_{-\infty}^{\infty} f\left(x_{k}, y, z\right) d z$

Examination of Equation (A-5) indicates that it involves both a summation and an integration. Although the indicated range of integration is from $-\infty$ to $+\infty$, this range can be restricted by defining the joint density to be 0 outside some indicated range on $T$, say for values of $T$ less than " $a$ " and greater than "b."

Functional relationships for each of the three probability density functions in Equation (A-3) must be derived.

\section{A-2.1 Derivation of $f\left(x_{k} \mid y, t\right)$}

For the kth component, $x_{k}$ is a Bernoulli trial (Parzen 1960). Therefore, the functional form for $\mathrm{f}\left(\mathrm{x}_{\mathrm{k}} \mid \mathrm{y}, \mathrm{t}\right)$ is given by

$f\left(x_{k} \mid y, t\right)=\left[R(t \mid y)_{k}\right]^{x_{k}}\left[1-R(t \mid y)_{k}\right]^{l-x_{k}}$

where $R(t \mid y)_{k}$ is the probability that the kth component will remain functional to $t$ and will fail only after t. A derivation of the function for $R(t \mid y)_{k}$ is given in Appendix $B$.

Examination of Equation (A-6) indicates the following:

for $x_{k}=1, f\left(x_{k}=1 \mid y, t\right)=R(t \mid y)_{k}$, and

for $x_{k}=0, f\left(x_{k}=0 \mid y, t\right)=1-R(t \mid y)_{k}$. 


\section{A-2.2 Derivation of $f(t \mid y)$}

By definition, the probability that $0 \leq \mathrm{T} \leq \mathrm{t}$, given $\mathrm{y}$, is expressed by Equation (A-4). Under the same assumption ${ }^{b}$ that $t$ is uniformly distributed,

$f(t \mid y)=\left\{\begin{array}{cl}\frac{1}{b-a} & \text { for } a \leq t \leq b, \text { and } \\ 0 & \text { otherwise }\end{array}\right.$

where

a $=$ the lower limit on $t$ and will usually be equal to 0

$\mathrm{b}=$ the upper limit on $\mathbf{t}$

If Equation (A-7) is substituted into Equation (A-4), then the probability that $0 \leq \mathrm{T} \leq \mathrm{t}$ given $\mathrm{y}$ is expressed by the following equation:

$\operatorname{Pr}(0 \leq T \leq t \mid y)=\int_{0}^{t}\left[\frac{1}{b-a}\right] d z=\frac{t}{b-a}$

\section{A-2.3 Derivation of $f(y)$}

Since $y$ is also a Bernoulli trial, the functional form for $f(y)$ is expressed by the following equation:

$f(y)=P^{y}(1-P)^{1-y}$

where

$\mathrm{P}=$ the enhancement component reliability

$1-\mathrm{P}=$ the enhancement component unreliability.

Examination of Equation (A-9) indicates the following:

when $\mathrm{y}=1, \mathrm{f}(\mathrm{y}=1)=P$, and

when $y=0, f(y=0)=1-P$.

b. This assumption may not always be appropriate and should be evaluated in any given application of the model. 


\section{A-2.4 Derivation of $f\left(x_{k}, y, t\right)$}

Substituting Equations (A-6), (A-7), and (A-9) into Equation (A-3) gives the following expression for $f\left(x_{k}, y, t\right)$ :

$$
f\left(x_{k}, y, t,\right)=\left[R(t \mid y)_{k}\right]^{x_{k}}\left[1-R(t \mid y)_{k}\right]^{1-x_{k}}\left[\frac{1}{b-a}\right][P]^{y}[1-P]^{1-y}
$$

Equation (A-10) is the joint probability density function and is needed to determine the expected value of $\mathbf{x}_{\mathbf{k}}$.

\section{A-2.5 The Expected Value of $x_{k}$ Given $y$ and $t$}

By definition, the conditional expected value of $x_{k}$ given $y$ and $t$ (i.e., the conditional reliability) is expressed by the following equation:

$$
\begin{aligned}
E\left(x_{k} \mid y, t\right) & =\sum_{x_{k}=0}^{1} x_{k} f\left(x_{k} \mid y, t\right) \\
& =\sum_{x_{k}=0}^{1} x_{k}\left[R(t \mid y)_{k}\right]^{x_{k}}\left[1-R(t \mid y)_{k}\right]^{1-x_{k}} \\
& =R(t \mid y)_{k} .
\end{aligned}
$$

Equation (A-11) gives the reliability of the kth component as a function of $t$ given $y$. It is also necessary to determine the unconditional reliability of the kth component.

\section{A-2.6 The Expected Value of $x_{k}$}

By definition, the expected value of $x_{k}$ is given by the following equation:

$$
E\left(x_{k}\right)=\sum_{x_{k}=0}^{1} \sum_{y=0}^{1} \int_{a}^{b} x_{k} f\left(x_{k}, y, t\right) d t
$$

Rearrange the summations and integration in Equation (A-12); let $a=0$, and let $f\left(x_{k}, y, t\right)$ be given by Equation $(\mathrm{A}-10)$. Then, $\mathrm{E}\left(\mathrm{x}_{\mathrm{k}}\right)$ is given by the equation 


$$
\begin{aligned}
E\left(x_{K}\right) & =\frac{1}{b} \sum_{y=0}^{l}[P]^{y}[1-P]^{1-y} \int_{0}^{b} \sum_{x_{k}=0}^{t} x_{k}\left[R(t \mid y)_{k}\right]^{x_{k}}\left[1-R(t \mid y)_{k}\right]^{1-x_{k}} d t \\
& =\frac{1}{b} \sum_{y=0}^{1}[P]^{y}[1-P]^{1-y} \int_{0}^{b} R(t \mid y)_{k} d t .
\end{aligned}
$$

The $\mathrm{E}\left(\mathrm{x}_{\mathrm{k}}\right)$, as given by Equation (A-13), is the reliability for the kth component. 


\section{A-3. RELIABILITY FOR N COMPONENTS OF A GIVEN TYPE}

Using the definition of conditional probability, the joint probability density of $\left(x_{1}, x_{2}, \ldots, x_{N}, y\right.$, t) can be expressed as follows:

$$
\begin{aligned}
f\left(x_{1}, \ldots, x_{N}, y, t\right) & =f\left(x_{1}, \ldots x_{N} \mid y, t\right) f(y, t) \\
& =f\left(x_{1}, \ldots, x_{N} \mid y, t\right) f(t \mid y) f(y)
\end{aligned}
$$

Functional forms for $f(t \mid y)$ and $f(y)$ are given by Equations (A-7) and (A-9). However, an equation must be developed for $f\left(x_{1}, x_{2}, \ldots x_{N} \mid y, t\right)$.

\section{A-3.1 Derivation of $f\left(x_{1}, \ldots, x_{N} \mid y, t\right)$}

If the success/failure outcomes associated with respective $x_{k}$ are independent, then

$$
f\left(x_{1}, x_{2}, \ldots, x_{N} \mid y, t\right)=f\left(x_{1} \mid y, t\right) \ldots f\left(x_{N} \mid y, t\right)
$$

An equation for each of the $k=1, \ldots, N$ components, that is, $f\left(x_{k} \mid y, t\right)$, was derived and is given by Equation (A-6).

Substitution of Equation (A-6) into Equation (A-15) yields

$$
f\left(x_{1}, \ldots, x_{N} \mid y, t\right)=\prod_{k=1}^{N}\left[R(t \mid y)_{k}\right]^{x_{k}}\left[1-R(t \mid y)_{k}\right]^{1-x_{k}}
$$

Equation (A-16) gives the conditional probability of the $\mathrm{N}$-tuple $\mathrm{e}^{\mathrm{c}}\left(\mathrm{x}_{1}, \ldots, \mathrm{x}_{\mathrm{N}}\right)$ given $\mathrm{y}$ and $\mathrm{t}$.

It is useful to define a random variable $X$.

Let

$$
\mathrm{X}=\sum_{\mathrm{k}=1}^{\mathrm{N}} \mathrm{X}_{\mathrm{k}}
$$

It is then desirable to determine the joint probability density of $x, y, t$. The definition of conditional probability can be used to obtain the joint density, as given by

c. See Parzen (1960) for the definition of an N-tuple. 
$f(x, y, t)=f(x \mid y, t) f(t \mid y) f(y)$

The functions $f(t \mid y)$ and $f(y)$ are given by Equations (A-7) and (A-9). However, it is necessary to develop an equation for $f(x \mid y, t)$.

\section{A-3.2 Derivation of $f(x \mid y, t)$}

Two functional forms for $f(x \mid y, t)$ can be developed, depending on whether the following equation is assumed:

$R(t \mid y)_{1}=R(t \mid y)_{2}=\ldots=R(t \mid y)_{N}=R(t \mid y)$.

\section{A-3.2.1 The $R(t \mid y)_{k}$ are Not Equal for $k=1,2, \ldots, N$}

Under the condition that the $R(t \mid y)_{k}$ are not equal for $k=1, \ldots, N$, a functional form for $f(x \mid y, t)$ can be developed.

For the purpose of providing insight into the derivation of $f(x \mid y, t)$, let $N=2$. Then, the following situations are possible:

$\begin{array}{ccc}\mathrm{x}_{1} & \mathrm{x}_{2} & \mathrm{x} \\ 0 & 0 & 0 \\ 0 & 1 & 1 \\ 1 & 0 & 1 \\ 1 & 1 & 2\end{array}$

Examination of the above combinations indicates the following:

$f(x=0 \mid y, t)=f\left(x_{1}=0, x_{2}=0 \mid y, t\right)$

and

$f(x=1 \mid y, t)=f\left(x_{1}=0, x_{2}=1 \mid y, t\right)+f\left(x_{1}=1, x_{2}=0 \mid y, t\right)$

and 


$$
f(x=2 \mid y, t)=f\left(x_{1}=1, x_{2}=1 \mid y, t\right)
$$

For $\mathrm{N}=2$, Equation $(\mathrm{A}-16)$ can be used to define

$$
f\left(x_{1}, x_{2} \mid y, t\right)=\prod_{k=1}^{2}\left[R(t \mid y)_{k}\right]^{x_{k}}\left[1-R(t \mid y)_{k}\right]^{1-x_{k}}
$$

Using Equation (A-23), the three expressions given by Equations (A-20), (A-21), and (A-22) can be written in terms of the following expression:

$$
f(x \mid y, t)=\sum_{\sum_{k=1}^{2} x_{k}^{\prime}=x} \prod_{k=1}^{2}\left[R(t \mid y)_{k}\right]^{x_{k}}\left[1-R(t \mid y)_{k}\right]^{1-x_{k}}
$$

where the summation in Equation (A-24) is over all combinations of $x_{1}$ and $x_{2}$ for which their sum is equal to $\mathrm{x}$.

Equation (A-24) can be generalized by replacing the 2 with $N$. Then

$$
f(x \mid y, t)=\sum_{\sum_{k=1}^{N} x_{k}=x} \prod_{k=1}^{N}\left[R(t \mid y)_{k}\right]^{x_{k}}\left[1-R(t \mid y)_{k}\right]^{1-x_{k}}
$$

\section{A-3.2.2 The $R(t \mid y)_{k}$ are Equal for $k=1, \ldots, N$}

Assume that $R(t \mid y)_{k}=R(t \mid y)$ for $k=1, \ldots, N$. Then, $f\left(x_{1}, x_{2}, \ldots, x_{N} \mid y, t\right)$ is given by

$$
\begin{aligned}
f\left(x_{1}, \ldots, x_{N} \mid y, t\right) & =f\left(x_{1} \mid y, t\right) \ldots f\left(x_{N} \mid y, t\right) \\
& =[R(t \mid y)]^{\sum_{k=1}^{N} x_{k}}[1-R(t \mid y)]^{N-\sum_{k=1}^{N} x_{k}} \\
& =[R(t \mid y)]^{x}[1-R(t \mid y)]^{N-x} .
\end{aligned}
$$


Therefore, when $R(t \mid y)_{k}=R(t \mid y)$, Equation (A-25) becomes

$$
f(x \mid y, t)=\sum_{\sum_{k=1}^{N} x_{k}=x}[R(t \mid y)]^{x}[1-R(t \mid y)]^{N-x}
$$

Since the probability associated with any combination of the $x_{1}, x_{2}, \ldots, x_{N}$ is constant for a specified value of $x$, the summation sign in Equation (A-27) can be replaced by a count of the number of combinations of $\mathrm{N}$ items taken $\mathrm{x}$ at a time. The number of combinations is given by

$\left(\begin{array}{l}N \\ x\end{array}\right)=\frac{N !}{x !(N-x) !}$

where

$$
\begin{aligned}
& \mathrm{x} ! \quad=(\mathrm{x})(\mathrm{x}-1)(\mathrm{x}-2) \ldots(1) \\
& \mathrm{N} ! \quad=(\mathrm{N})(\mathrm{N}-1)(\mathrm{N}-2) \ldots(1) .
\end{aligned}
$$

Equation (A-27) can then be expressed as follows:

$$
f(x \mid y, t)=\left(\begin{array}{l}
N \\
x
\end{array}\right)[R(t \mid y)]^{x}[1-R(t \mid y)]^{N-x}
$$

A specification of $y$ and $t$ in Equation (A-29) results in a constant value of $R(t \mid y)$. Consequently, $f(x \mid y, t)$ is binomially distributed.

\section{A-3.3 The Expected Value of $\bar{x}$ Given $y$ and $t$}

It will be convenient to determine the expected value of $x$, given $y$ and $t$, after which the expected value of $\bar{x}$, given $y$ and $t$, will also be obtained.

By definition, the expected value of $\mathrm{x}$ given $\mathrm{y}$ and $\mathrm{t}$ is as follows:

$$
E(x \mid y, t)=\sum_{x=0}^{N} x f(x \mid y, t)
$$


Substituting Equation (A-29) into Equation (A-30) leads to the following relationship:

$$
\begin{aligned}
E(x \mid y, t) & =\sum_{x=0}^{N} x\left(\begin{array}{l}
N \\
x
\end{array}\right)[R(t \mid y)]^{x}[1-R(t \mid y)]^{N-x} \\
& =N R(t \mid y) .
\end{aligned}
$$

The expected value of $\bar{x}$, given $\mathrm{y}$ and $\mathrm{t}$, is then as follows:

$$
\begin{aligned}
E(\bar{x} \mid y, t) & =E\left[\frac{x}{N} \mid y, t\right]=\frac{1}{N} E(x \mid y, t) \\
& =R(t \mid y) .
\end{aligned}
$$

Referring to Equations (A-11) and (A-32), it can be noted that

$$
E\left(x_{k} \mid y, t\right)=E(\bar{x} \mid y, t)=R(t \mid y)
$$

Equation (A-33) is a consequence of the following assumptions:

- Independence of the $x_{k}$

- $\quad R(t \mid y)_{k}=R(t \mid y) ;$ for $k=1, \ldots, N$

Equation (A-32) can be considered the conditional reliability of the population of $\mathrm{N}$ components, given $t$ and $y$. It is also desirable to determine the unconditional reliability.

\section{A-3.4 The Expected Value of $\bar{x}$}

By definition, the expected value of $\mathrm{x}$ is given by

$E(x)=\sum_{y=0}^{1} \sum_{x=0}^{N} \int_{a}^{b} x f(x, y, t) d t$. 
Substituting Equation (A-18) into Equation (A-34) gives

$E(x)=\sum_{y=0}^{1} \sum_{x=0}^{N} \int_{a}^{b} x f(x \mid y, t) f(t \mid y) f(y) d t$.

Reorder the summations and integration in Equation (A-35); let $a=0$, and let $f(x \mid y, t), f(t \mid y)$, and $f(y)$ be given by Equations (A-29), (A-7), and (A-9), respectively. Then

$E(x)=\frac{1}{b} \sum_{y=0}^{1}[P]^{y}[1-P]^{1-y} \int_{0}^{b} \sum_{x=0}^{N} x\left(\begin{array}{l}N \\ x\end{array}\right)[R(t \mid y)]^{x}[1-R(t \mid y)]^{N-x} d t$

The quantity

$\sum_{x=0}^{N} x\left(\begin{array}{c}N \\ x\end{array}\right)[R(t \mid y)]^{x}[1-R(t \mid y)]^{N-x}=N R(t \mid y)$

so

$E(x)=\frac{N}{b} \sum_{y=0}^{1}(P)^{y}(1-P)^{1-y} \int_{0}^{b} R(t \mid y) d t$.

Furthermore,

$$
\begin{aligned}
E(\bar{x}) & =E\left[\frac{x}{N}\right]=\frac{1}{N} E(x) \\
& =\frac{1}{b} \sum_{y=0}^{1}(P)^{y}(1-P)^{1-y} \int_{0}^{b} R(t \mid y) d t \\
& =r_{i j} .
\end{aligned}
$$

Equation (A-39) gives the general component reliability model for the jth component within the ith equipment sequence. 


\section{A-4. REFERENCES}

Mood, Alexander M., and Franklin A. Graybill, 1963, Introduction to the Theory of Statistics, McGraw-Hill, New York.

Parzen, E. Manuel, 1960, Modern Probability Theory and Its Applications, John Wiley and Sons, Inc., New York. 
Appendix B

\section{Derivation of $\mathbf{R}(t \mid \mathbf{y})$}

B-1 
B-2 


\section{Appendix B}

\section{Derivation of $R(t \mid y)$}

The derivation of Equation (5-5) is discussed in Appendix B. For the continuous random variable $T, R(t \mid y)$ is the probability, given $y$, that the component will not fail for $0 \leq T \leq t$, and $F(t \mid y)=1-R(t \mid y)$ is the probability, given $y$, that the component will fail by time $t$.

Consider two adjacent intervals 0 to $t$, and $t$ to $t+\Delta t$, where $\Delta t$ is small. Let $\mathrm{A}$ be the event that the component does not fail in the interval 0 to $t$, and let $\mathrm{B}$ be the event that the component does not fail in the interval t to $t+\Delta t$. Then, the probability of $A$ is $P(A)_{y}=R(t \mid y)$. However, the probability of B depends on whether or not A has occurred.

If the component failed in the interval 0 to $t$, (that is, the event $\bar{A}$ ), then the probability of $B$ given $\overline{\mathbf{A}}$ is equal to 0 . In other words, $\mathrm{P}(\mathrm{B} \mid \overline{\mathrm{A}})_{\mathrm{y}}=0$ since, after a component has failed, it remains defective.

On the other hand, if the component does not fail in the interval 0 to $t$, then the probability of $B$ given $\mathrm{A}$ is

$\mathrm{P}(\mathrm{B} \mid \mathrm{A})_{\mathrm{y}}=\frac{\mathrm{P}(\mathrm{AB})_{\mathrm{y}}}{\mathrm{P}(\mathrm{A})_{\mathrm{y}}}$

where $\begin{aligned} P(A B)_{y}= & R(t+\Delta t \mid y) \text {, which is the probability that the component did not fail prior to } \\ & t+\Delta t\end{aligned}$

$\mathrm{P}(\mathrm{A})_{\mathrm{y}}=\mathrm{R}(\mathrm{t} \mid \mathrm{y})$, which is the probability that the component did not fail prior to $t$.

Let the probability of the component failure in the interval t to $t+\Delta t$ be $\lambda(t)_{y} \Delta t$. Then, $1-\lambda(t)_{y} \Delta t$ is the probability of the component not failing in the interval $t$ to $t+\Delta t$. In other words,

$P(B \mid A)_{y}=1-\lambda(t)_{y} \Delta t=\frac{R(t+\Delta t \mid y)}{R(t \mid y)}$

Equation (B-2) can be used to obtain the following equation:

$$
\begin{aligned}
R(t+\Delta t \mid y) & =R(t \mid y)\left[1-\lambda(t)_{y} \Delta t\right] \\
& =R(t \mid y)-R(t \mid y) \lambda(t)_{y} \Delta t
\end{aligned}
$$


Equation (B-3) can be used to obtain

$-\lambda(t)_{y} R(t \mid y)=\frac{R(t+\Delta t \mid y)-R(t \mid y)}{\Delta t}$

In the limit as $\Delta t \rightarrow 0$, Equation (B-4) becomes

$-\lambda(t)_{y} R(t \mid y)=\frac{d R(t \mid y)}{d t}$

or

$-\lambda(t)_{y} d t=\frac{d R(t \mid y)}{R(t \mid y)}$

Recalling from differential calculus that $d \ln z=\frac{1}{z} d z$, then if $z=R(t \mid y)$, Equation (B-6) can be expressed as follows:

$-\lambda(t)_{y} d t=d[\ln R(t \mid y)]$

After introducing a dummy variable ( $\omega$ ) and integrating, Equation (B-7) becomes

$-\int_{0}^{t} \lambda(\omega)_{y} d \omega=\ln R(t \mid y)$

Taking the antilog, base e, of both sides of Equation (B-8) gives

$R(t \mid y)=e^{-\int_{0}^{j} \lambda(\omega) d \omega}$

Feller (1957) and Dubey (1965) provide additional insight into the derivation of Equation (B-9). 


\section{REFERENCES}

Feller, William, 1957, An Introduction to Probability Theory and Its Applications, Volume I, John Wiley \& Sons, Inc., New York.

Dubey, Satya D., 1965, "Asymptotic Properties of Several Estimators of Weibull Parameters," Technometrics, Volume 7, No. 3, August. 